\title{
1 The effect of sonication and high pressure homogenisation on the properties of pure
}

\section{cream}

3 Jayani Chandrapala ${ }^{\mathrm{a}, \mathrm{b}}$, Lydia Ong ${ }^{\mathrm{a}, \mathrm{e}, \mathrm{f}}$, Bogdan Zisu ${ }^{\mathrm{c}, \mathrm{d}, e}$, Sally L. Gras ${ }^{\mathrm{a}, \mathrm{e}, \mathrm{f}}$, Muthupandian

$4 \quad$ Ashokkumar ${ }^{\mathrm{a}, \mathrm{e}}$, Sandra E. Kentish ${ }^{\mathrm{a}, \mathrm{e}^{*}}$

5

$6{ }^{a}$ School of Chemistry/ Department of Chemical and Biomolecular Engineering, University of

7 Melbourne, VIC 3010, Australia

$8{ }^{b}$ Advanced Food Systems Unit, College of Health \& Biomedicine, Victoria University, VIC 9 3030, Australia

$10{ }^{c}$ Dairy Innovation Australia, Werribee, VIC 3030, Australia

$11{ }^{d}$ School of Applied Sciences, College of Science, Engineering and Health, RMIT University,

12 Australia

$13{ }^{e}$ The ARC Dairy Innovation Hub, the University of Melbourne, VIC 3010, Australia

14 The Bio21 Molecular Science and Biotechnology Institute, The University of Melbourne, 15 VIC 3010, Australia

17 *Corresponding Author: Sandra Kentish

Email address: sandraek@unimelb.edu.au 
23 The homogenisation of milk and cream has been widely studied, but the effect of sonication on the structural and functional properties of cream is not well known. In this study, raw milk, ultrafiltration retentate and cream samples were sonicated at $20 \mathrm{kHz}$ and the rennet and acid gelation properties of these sonicated samples investigated. High pressure homogenisation at 80 bar was also performed for comparison. Sonication of raw milk and retentate samples led to a decrease in the fat globule size. Conversely, the fat globules in cream samples sonicated at $<10^{\circ} \mathrm{C}$ flocculated to form grapelike structures, whereas the cream samples sonicated at $50^{\circ} \mathrm{C}$ did not form such aggregates. High pressure homogenisation at $50^{\circ} \mathrm{C}$ led to similar flocculated structures, but these were not observed at low temperatures. This suggests a potential benefit of sonication technology in allowing low temperatures to be utilised for cream homogenisation, reducing energy demand. However, a gel made using cheese-milk with sonicated cream resulted in separation of a fat layer rather than the incorporation of the fat globules into the gel matrix. Rennet gelation properties of both the sonicated or homogenised samples were significantly superior to a native control sample where the resultant gels had shorter coagulation times and decreased syneresis.

Keywords: Cheese milk; homogenisation; sonication; rennet gels; acid gels 


\section{Introduction}

Milk fat is present in milk as droplets of diameter in the range of $1-10 \mu \mathrm{m}$. These globules are covered with a natural milk fat globule membrane (MFGM) composed mainly of phospholipids and enzymes. The sensorial and rheological properties of many dairy products depend greatly on the size distribution of the fat globules and on the composition of the membrane (Cho, Lucey, \& Singh, 1999; Lopez \& Dufour, 2001). Reduction of the fat globule size and the consequent disruption of the fat globule membrane through ultrasonication alone or in combination with conventional homogenisation may lead to a range of new dairy products with different physico-chemical and functional properties. Although, such fat globule size reduction is not desirable for Cheddar cheese manufacture, it has many benefits in the manufacture of soft cheeses and dairy gels where the resulting high moisture content, creamier, smoother and softer textures are desirable. Further, the smaller fat globules are more sensitive to the influence of the lipolytic enzymes in making specialised products, such as blue cheese.

The milk fat globule membrane (MFGM) does not interact with the protein network in native dairy gels and so the fat globules act mainly as an inert filler or structure breaker (Milchaski et al., 2004). However, when such dairy systems are subjected to shear, the fat globules are disrupted and their average diameter decreases significantly (Bernudez-Aguirre \& BarbosaCanovas, 2010). Milk homogenization also disrupts the fat globule membrane, which is replaced by membrane fragments complexed with casein (Tunick, Van Hekken, Cooke, Smith \& Malin, 2000). These homogenized fat globules are then able to form cross links with the casein network, and this effect is enhanced by their large surface area (Metzger \& Mistry, 1995). Michalski et al., (2002a) found that homogenized milk contained three types of fat particles: (i) regular milk fat globules with a fraction of the surface covered by casein micelles, (ii) tiny native milk fat globules around $100 \mathrm{~nm}$ in diameter that are not affected by 
homogenization due to their size and (iii) small newly formed lipid-protein complexes with new membrane composed mainly of casein. Dalgleish, Tosh \& West, (1996) concluded that casein micelle fragments, rather than intact micelles, are adsorbed on the globules during micro fluidization of milk. They attributed the disruption of the casein micelles to the forces encountered during the shearing process, which are experienced by micelles adsorbing at the fat/serum interface. Hayes, Fox, \& Kelly, (2005) also found that fat globules in high pressure (HP) homogenised milk are surrounded by a layer of casein micelle fragments rather than intact casein micelles. In contrast, Tosh \& Dalgelish (1998) stated that disrupted fat globules are mainly bound by intact casein micelles.

Several studies have found that such changes during homogenisation (Michalski et al., 2002a,b, 2004; Sandra \& Dalgleish 2007; Shaker, Abu-Jdayl, Jumah, \& Ibrahim, 2002; Titapiccolo, Alexander, \& Corredig, 2010; Yiran, Lee, \& Anema, 2011; Zamora, Ferragut, Jaramillo, Guamis, \& Trujillo, 2006) and micro fluidization (Ciron, Gee, Kelly, \& Auty, 2012; Lemay, Paquin, \& Lacroix, 1994; Path, Gellman, Schimdt, \& Herforth-Kennedy, 1989; Tunick et al., 2000; van Hekken, Tunick, Marlin, \& Holsinger, 2007) influence milk gelation kinetics and the resulting milk gel properties. The reduction of fat globule size implies a dispersion of fat into an increased number of smaller globules. The newly built surfaces are modified by the presence of adhering casein particles and become part of the para-casein network, hindering shrinkage of the network and thus lowering the syneresis and fat loss (Lemay et al., 1994). Green, Marshal, \& Glover, (1983) observed that curds from conventionally homogenized milk had a less coarse protein network, which retained moisture more effectively than curds from non homogenized milks. However, the formation of complexes between casein and MFGM decreases the amount of casein available to form stronger casein-casein bonds (Lemay et al., 1994). In turn, this affects cheese body and 
texture by a reduction of curd firming (Emmons, Kalab, \& Larmond, 1980; Green et al., 1983). The weaker texture is also due to the new milk fat globules participating directly in the network instead of remaining trapped within the casein matrix.

Similar fat globule - protein complexes have also been observed when milk is subjected to ultrasonication (Michalski et al., 2002a). During exposure to an acoustic field, microbubbles are generated within the dairy fluid. The collapse of these microbubbles induces localised shear forces that are readily capable of disrupting fat globules. Bernudez-Aguirre, Mawson, \& Barbosa-Canovas, (2008) found that the sheared fat globules had a roughened granular surface due to the interaction between the disrupted MFGM and nearby casein micelles. Such changes induced noticeable improvements in the quality of Hispanic Cheese (handmade cheese consumed in Latin America) when the cheese milk was sonicated at $63^{\circ} \mathrm{C}$ for $30 \mathrm{~min}$ (Bermudez-Aguirre \& Barbosa-Canovas, 2010). The cheese had a whiter colour, higher cheese yield and better textural and micro-structural properties with only a minor degree of syneresis. Increased water holding capacities for Emmental cheese and high lipolytic enzyme activity for blue cheeses has also been achieved through a reduction in fat globule size using sonication of the feed milk (Milchalski et al., 2004).

While there is much work on the use of both homogenisation and sonication of cheese milk prior to gel formation, there is no work available on the sonication of the raw cream alone; prior to addition to cheese milk. Cream is commonly used to increase the fat concentration of milk for the production of soft, cream or high fat hard cheeses. It is a common practice to homogenize this cream before addition, to improve texture (Madadlou, Mousavi, Asl, EmamDjome, \& Zargaran, 2007; Sanchez, Beauregard, Chassagne, Bimbenet, \& Hardy, 1996). In this study, we have looked at the effect of sonication on cream as a comparison to the effect 
observed during homogenisation. Separate sonication of cream prior to addition to the cheese milk could avoid the casein-MFGM interactions that reduce the capacity for these proteins to participate in gel formation. The present study uses cream systems containing $\sim 40 \%$ fat which were subjected to sonication (50 $\mathrm{W}$ for $1 \mathrm{~min}$ ) or homogenisation (80 bar) prior to addition to standardised cheese milk. The acid and rennet gelation properties were then investigated using these cheese milk systems.

\section{Materials and methods}

\subsection{Materials}

Raw milk, ultrafiltrate (UF) retentate, skim milk (SM), skim milk concentrate (SMC) and cream were obtained from a local Victorian dairy manufacturer. The composition of these samples, as supplied by the manufacturer, is given in Table 1 .

\section{Table 1 here}

Cheese-milk is defined as the milk standardised for the manufacture of Cheddar cheese, obtained by blending skim milk with skim milk concentrate and cream to obtain the desired protein and fat content of $3.8 \% \mathrm{w} / \mathrm{w}$ and $4.6 \% \mathrm{w} / \mathrm{w}$, respectively. Three types of cheese-milk were investigated in this study:

1. A blend of SM, SMC and cream with no treatment (native);

2. A blend of SM, SMC and sonicated cream

3. A blend of SM, SMC and homogenised cream

The milk was blended by hand stirring for 1 minute and each mixture was pasteurized at $85^{\circ} \mathrm{C}$ for $30 \mathrm{~min}$. 
143 Batch solutions of milk and cream were sonicated in a glass vessel equipped with a cooling 144 jacket using a $20 \mathrm{kHz}, 450 \mathrm{~W}$ Ultrasonic horn (19 mm diameter, Branson Sonifier 450,

145 Danbury, CT). To maintain a constant energy density, samples of $40 \mathrm{ml}$ were sonicated at an 146 amplitude of $60 \%$ and samples of $60 \mathrm{ml}$ were sonicated at an amplitude of $40 \%$. The power 147 draw, as determined from a single-phase energy cost meter (Arlec, Victoria, Australia), was measured as 101 and $189 \mathrm{~W}$ under these conditions, giving an input energy density of $152 \pm 3$ $\mathrm{J} / \mathrm{ml}$ for one minute sonication in both cases. The settings equated to delivered power levels of $31 \pm 2 \mathrm{~W}$ and $50 \pm 2 \mathrm{~W}$ as determined by calorimetry (Contamine, Wilhelm, Berlan \& Delmas, 1995). During sonication, water was continuously circulated through the cooling 152 jacket to maintain the desired sample temperature.

153 The homogeniser used was a GEA Panda PLUS 1000 (GEA Nitro Savi, Parma, Italy) equipped with a cell disruption valve. Single stage and single pass homogenisation was performed on $500 \mathrm{ml}$ of solution at an operating pressure of 80 bar. In this case, the power drawn was $570 \mathrm{~W}$. The flow rate of the solution was set at $3.73 \mathrm{ml} / \mathrm{s}$ to provide an identical input energy density of $153 \pm 3 \mathrm{~J} / \mathrm{ml}$.

\subsection{Particle Size Distribution}

The particle size distribution of the fat globules in samples was measured using a Mastersizer 2000 (Malvern Instruments, Malvern, UK) using a refractive index for milk fat of 1.460

162 (Yiran et al., 2011). The milk sample was diluted (1:1) in ethylenediamine tetraacetic acid (EDTA; $50 \mathrm{mM}, \mathrm{pH}$ 7). The milk samples were then added into the circulating cell with/without $0.05 \%$ sodium dodecyl sulphate (SDS). EDTA was used to dissociate casein micelles from the fat globules and SDS added to dissociate any aggregates containing fat 
globules. The volume weighted mean diameter $\mathrm{D}[4,3]$ was calculated by the Mastersizer 2000 software. Triplicate measurements were carried out for each of the samples.

\subsection{Rennet- or acid- induced gel preparation}

Rennet-induced gels were prepared from the blended and pasteurised milk samples, to replicate cheddar cheese gels. The milk was first tempered to $33^{\circ} \mathrm{C}$ before inoculation with the starter culture. A freeze-dried mixed strain direct vat set (DVS) mesophilic starter culture containing Lactococcus lactis subsp. lactis and L. lactis subsp. cremoris (Chr. Hansen, Bayswater, Victoria, Australia) was added at a concentration of $0.05 \mathrm{~g} / \mathrm{l}$ of milk. When the $\mathrm{pH}$ of the milk reached 6.50, rennet (Hannilase, $690 \mathrm{IMCU} / \mathrm{ml}$; Chr. Hansen) was added $(0.1 \mathrm{ml} / \mathrm{l}$ of milk). The milk was allowed to coagulate for a period of $45 \mathrm{~min}$ at $33^{\circ} \mathrm{C}$ following the standard protocol for Cheddar cheese production (Ong, Dagastine, Kentish, \& Gras, 2010).

The acid-induced gel was prepared by adding 2.5\% (w/w) Glucono Delta Lactone (SigmaAldrich, Australia) to the pasteurised milk samples, which were then incubated at $33^{\circ} \mathrm{C}$ to form an acid gel for 2 hours.

\subsection{Sample Analysis}

The viscoelastic properties of the acid and rennet gels were analysed using an Advanced Rheometric Expansion System (ARES) rheometer (TA Instruments, New Castle, USA) equipped with a cup (34 mm diameter) and bob (32 mm diameter, $33 \mathrm{~mm}$ length) accessory. A sample of cheese-milk $(15 \mathrm{ml})$ that had been inoculated with starter culture $(0.05 \mathrm{~g} / \mathrm{l})$ and ripened to $\mathrm{pH}$ of 6.5 was added to the cup immediately after the addition of rennet $(0.1 \mathrm{ml} / \mathrm{l})$. The temperature of the milk was maintained at $33^{\circ} \mathrm{C}$. A dynamic time sweep (9000 s) analysis at angular frequency of $5 \mathrm{rad} / \mathrm{s}$ and $1 \%$ strain was used to analyse the changes in storage modulus (G') as the milk coagulated following a published protocol (Ong, Dagastine, 
191 Kentish, \& Gras, 2012). The gelation time was defined as the time taken for each sample to reach $\mathrm{G}^{\prime}=5 \mathrm{~Pa}$.

193

Gel syneresis was defined as the ratio of the liquid mass expelled during centrifugation (Heraeus Biofuge Primo, Germany) at $1449 \mathrm{~g}$ for $20 \mathrm{~min}$ and the weight of the original sample (Zisu et al., 2011).

197

The gel strength of the samples was determined using a TAXT2 texture analyzer (Stable Micro Systems, Godalming, England) equipped with $2 \mathrm{~kg}$ load cell and a cylindrical acrylic probe (2 $\mathrm{cm}$ in diameter and $35 \mathrm{~mm}$ in height) as described by Ong, Dagastine, Kentish, \& Gras, (2011). All samples were analysed $4 \mathrm{~h}$ after the gel had set. For the rennet gels, this was $4 \mathrm{~h}$ and 45 minutes after rennet addition, while for the acid gels this was a total of six hours after acid addition. A test speed of $1 \mathrm{~mm} / \mathrm{s}$ was used to compress the sample to $50 \%$ of the original height $(30 \mathrm{~mm})$. The yield stress was defined as the force required to deform or fracture the sample. The maximum force measured was used as a measure of gel strength. A total of three gel samples were analysed for each processed milk preparation.

The gel samples formed from the process milk were prepared for observation by Confocal Laser Scanning Microscopy (Leica Microsystems, Heidelberg, Germany), as previously reported in Ong et al., (2011). Fat globules were stained with Nile red and protein stained with FCF fast green. The MFGM was stained with lectin wheat germ agglutinin WGA488. A one way ANOVA with $95 \%$ confidence interval was used to determine statistical significance, where $\mathrm{p}<0.05$ were considered statistically significant. 


\subsection{Effects of ultrasound and homogenisation on the raw ingredients}

The $\mathrm{D}[4,3]$ of fat globules in raw and sonicated milk are presented in Table 2. Native raw milk had a $\mathrm{D}[4,3]$ of $\sim 3.8 \mu \mathrm{m}$. With prolonged sonication at $31 \mathrm{~W}$ for $30 \mathrm{~min}$, the value decreased to $1.5 \mu \mathrm{m}$, reflecting smaller fat globules. Increasing the power level at the same time interval further decreased the size of fat globules, giving a $\mathrm{D}[4,3]$ of $160 \mathrm{~nm}$. Most importantly when the energy densities were kept constant at $\sim 153 \mathrm{~J} / \mathrm{ml}$ during sonication at $31 \mathrm{~W}$ and $50 \mathrm{~W}$ for $1 \mathrm{~min}$, the milk solutions contained fat globules with similar $\mathrm{D}[4,3]$ of $\sim 3.7 \mu \mathrm{m}$ and $\sim 3.6 \mu \mathrm{m}$, respectively. These data are consistent with previous observations using micro fluidisation or homogenisation, where particle size ranges from $2 \mu \mathrm{m}$ to $0.5 \mu \mathrm{m}$ were reported depending on the intensity of the process (Hayes et al., 2005; Lemay et al., 1994; Michalski et al., 2002a, 2004; Thiebaud, Dumay, Picart, Guirand, \& Cheftel, 2003; van Hekken et al., 2007). Sonication induced similar changes in the size of fat globules in UF retentate (Table 2). The fat globules present in the UF solution were a little larger than the fat globules present in raw milk. This may be due to the incorporation of some whey proteins onto the MFGM surface under the shear forces involved in membrane processing (Ye, Anema, \& Singh, 2004). Alternatively, the higher viscosity of the UF retentates as compared to raw milk may have meant that reduced shear forces acted on the fat globules. Increasing sonication time or power decreased the average fat globule size.

Table 2 here

237 Figure 1 shows CLSM images of the fat globules present in (A) raw milk \& (B) UF retentate 238 before and after sonication. These images confirm the presence of the disrupted fat globules and smaller fat globules following sonication. The CLSM images also show that the disrupted MFGM is coated by a thick layer of casein/casein micelles (Fig 1Aii and Bii). Increasing the 
treatment time and power level leads to the complete disruption of the MFGM, leading to the

242 fat globules being fully coated by proteins. This was especially notable at $50 \mathrm{~W} / 30 \mathrm{~min}$

243 (4620 J/ml). The CSLM data are consistent with the particle size data presented in Table 2.

244 Acoustic cavitation generated through sonication results in physical effects such as 245 shockwave formation and high turbulence (Chandrapala et al., 2011). The resultant large 246 shear forces break down the fat globules.

\subsubsection{Cream}

Table 2 shows the $\mathrm{D}[4,3]$ of fat globules present in cream samples sonicated at $50 \mathrm{~W}$ for different times below $10{ }^{\circ} \mathrm{C}$ and at $50{ }^{\circ} \mathrm{C}$. The native cream sample showed a $\mathrm{D}[4,3]$ of $\sim 4.0$ $\mu \mathrm{m}$. Sonication for $30 \mathrm{~s}$ below $10{ }^{\circ} \mathrm{C}$ led to an increase in $\mathrm{D}[4,3]$ suggesting flocculation of the fat globules. However, prolonged sonication or with the addition of SDS led to decreased $\mathrm{D}[4,3]$ values (Table 2). These results suggest that sonication at shorter times result in flocculation of fat globules; but that these aggregates are readily dispersed either by prolonged sonication or the use of SDS. These results can be confirmed by CSLM images (Fig 2A). CSLM images showed flocculated aggregates $30 \mathrm{~s}$ of sonication but these disappeared at longer times. Images of fat stained with WGA 488 for the MFGM also show that these flocculated fat globules have lost their MFGM and are coated by milk proteins (Fig 2B). At this stage, it is not fully understood as to why the fat globules flocculate at shorter sonication times but it can be suggested that shorter sonication times break down the MFGM so that the fat globules lose their stability. These disrupted fat globules can attach to proteins and form protein-protein interactions that cause clumping. However, prolonged sonication can break down these flocculated fat globules through the strong shear forces generated through acoustic cavitation. 
Figure 3 shows CLSM images of cream samples sonicated under the two temperature conditions $\left(<10{ }^{\circ} \mathrm{C}\right.$ and $\left.50{ }^{\circ} \mathrm{C}\right)$. The flocculated grapelike structures were observed in samples sonicated at low temperature, whereas sonication at high temperature resulted in smaller globule sizes. These differences are also clear from the size distributions of the fat globules shown in Figure 4. Tunick et al., (2000) also found a greater reduction in fat globule size with increasing temperature during microfluidisation and attributed this to the physical state of the fat. Much of the fat is in the solid state when sheared at lower temperatures whereas at high temperatures the fat is in the liquid state and thus can be easily fragmented into tiny droplets. Furthermore, at higher temperatures, an increase in the number of cavitation events per unit time is usually observed, although the collapse is less violent 276 (Kentish and Feng, 2014).

\section{Figure 3 here}

\section{Figure 4 here}

Cream samples conventionally homogenised at similar temperatures and energy densities were also analysed (Fig 5). In this case, homogenisation at high temperature resulted in the formation of the flocculated fat globule structures, whereas these were absent at the lower temperature. These results are again reflected in the particle size distribution (Fig 4). Native cream samples at $50^{\circ} \mathrm{C}$ showed a peak at $\sim 5 \mu \mathrm{m}$ with a small shoulder at $1 \mu \mathrm{m}$. High temperature homogenisation led to an increased particle size of $\sim 50 \mu \mathrm{m}$. In contrast, low temperature homogenisation led to only a slight broadening of the central peak at $5 \mu \mathrm{m}$ and an increase in the shoulder at $1 \mu \mathrm{m}$. A broadening of the size distribution was also observed for single stage ultrahigh pressure homogenisation of warmed milk at $300 \mathrm{MPa}$ (Thiebaud et al., 2003). The authors of this prior study suspected that the formation of larger particles was due to unfolding and aggregation of whey proteins at the surface of the newly created 
droplets. Cream samples conventionally homogenised at $50^{\circ} \mathrm{C}$ contained a large amount of 10-100 $\mu$ m particles (Fig 4). It should be noted that Koh et al., (2014) showed that cavitation did not occur during conventional homogenisation with the conditions used here.

\section{Figure 5 here}

3.2.Effects of ultrasound and homogenisation on rennet- and acid- induced gelation properties

The addition of homogenised or sonicated cream into cheese milk reduced the rennet gelation time by more than half, relative to the use of native cream $(\mathrm{P}<0.05)$ (Table 3). The rennetinduced gelation time of the control batch was $\sim 40$ min whereas homogenisation and sonication gave gelation times of 12 and $15 \mathrm{~min}$, respectively. In contrast, there was no statistically significant change for acid gelation. Zamora et al. (2006) also found that the use of a homogenised cheese milk results in a significantly lower rennet clotting time (RCT) relative to raw milk. The lower RCT of homogenized milks could be explained by the fact that most $\kappa$-casein is located on the micelle surface. As the casein enrobes the fat globules, the $\kappa$ - casein level is effectively diluted and a smaller critical level of $\kappa$-casein hydrolysis is required to start coagulation (Guinee et al., 1997). Furthermore, homogenization increases the surface area of available casein, making the $\kappa$-casein more available for chymosin action and thus, reducing the RCT (Ghosh, Steffl, Hinrichs, \& Kessler, 1994).

\section{Table 3 here}

Gel strength and yield stress did not change, within experimental error (Table 3), when homogenised or sonicated cream was used. This is in contrast to other work such as that by Ghosh et al., (1994), Humbert. Drion, Guerrin, \& Alais, (1980), Lemay et al., (1994), Robson \& Dalgleish, (1984) \& Zamora et al. (2006). These workers observed a loss in curd firmness when homogenisation or microfluidisation was used. The loss of gel strength was attributed to a greater dispersion of fat in the curd, to a reduced number of casein particles available to 
form a strong network, or to the small fat globules that are entrapped in the gel disrupting the continuity of gel structure and acting as weak centres in the gel.

Syneresis was lowered by more than half with conventional homogenisation in comparison to the control sample for the rennet gel. Sonication also led to a significant decrease in syneresis as compared to the untreated control. This decrease in syneresis is consistent with the literature. Bermudez-Aguirre \& Babosa-Canovas (2010) found less syneresis for queso fresco cheese made using sonicated milk compared to cheese made from thermally treated milk and syneresis decreased further with increase in sonication time. The decrease was attributed to disrupted fat particles and a reorganization of the proteins to form protein-fat complexes within the cheese matrix.

Figure 6 shows a typical G' vs time plots for rennet and acid gels prepared using native, homogenised or sonicated cream. Sonication and homogenisation both led to increased G' compared to the control for rennet gels, with the highest G' measured with homogenisation. Van Hekken et al. (2007) found that micro fluidization of cheese milk resulted in Mozzarella cheeses that showed more elastic than viscous properties, indicating that their internal structure stretched more and flowed less when subjected to a low strain. This is in agreement with our own results. Others find that if the interfacial material on the fat globule interacts with the casein network, $G^{\prime}$ increases with the volume fraction (Cho et al., 1999) of these globules and as their size decreases (Xiong, Aguilera, \& Kinsella, 1991; Zhou \& Mulvaney, 1998). Thus, fat globules covered by caseins increase the modulus of rennet gels but the yield stress is not significantly different.

Conversely, changes in G' were insignificant for the acid induced gels. During acidification, the net negative charge of the casein micelles is neutralized, causing a reduction in the 
amphiphilic character of the $\beta$ and $\kappa$ caseins and increasing the solubility of calcium

341 phosphate. Electrostatic repulsion between the micelles is weakened and $\alpha_{\mathrm{s}}$ caseins depolymerise leading to aggregation and formation of chains and clusters linked together as a three dimensional network. In contrast, rennet coagulation is primarily through enzymatic hydrolysis, where $\kappa$-casein is cleaved by rennet at the $\mathrm{Phe}_{105}-\mathrm{Met}_{106}$ bond, resulting in altered casein micelles that are susceptible to aggregation. Rennet gelation occurs earlier in Figure 6, as it is less dependent on $\mathrm{pH}$ and the three dimensional network forms faster compared to acid gelation. The slower acid gelation time ( 1500 s compared to $900 \mathrm{~s})$ possibly allows casein particles and fat globules to re-arrange within the acid gel, increasing the contact between casein particles and leading to a gel with a higher storage modulus, regardless of fat globule size.

\section{Figure 6 here}

\section{Figure 7 here}

Figure 7 shows the CSLM images of the (A) rennet and (B) acid gels. Each fat globule retained its spherical globular structure within the rennet gel. The casein networks appear as strands of aggregated casein micelles with entrapped lipid droplets. The rennet gels appear more cohesive than the acid gels, with fewer and larger pores, consistent with observations in the literature (Green, Hobbs, Marant, \& Hill, 1978).

Interestingly, some of the grapelike structures observed initially within the sonicated cream samples persist within the gel network. However, some of the larger fat globule aggregates do not appear to interact with the casein network (Fig 7Aiii and Biii). Conversely, the fat globule aggregates in the homogenised sample appear better integrated (Fig 7Aii and Bii). Visually, the sonicated gels also showed a fat layer on the surface indicating the separation of coalesced fat globules. A lower sonication power may have the potential of preventing this 
fat separation while still achieving an improved syneresis and shorter processing time, consistent with the homogenised sample.

The localised high temperature conditions generated during acoustic cavitation can lead to the formation of radicals in some conditions (Ashokkumar et al., 2008). There is a possibility that these radicals may oxidise lipids in the system. However, Ashokkumar et al. (2008) have reported that generation of such radicals at $20 \mathrm{kHz}$ is insignificant due to the low number of active cavitation bubbles. Similarly, Juliano et al., (2014) have studied the generation of volatile compounds by lipid oxidation in raw and heat treated milk samples subjected to sonication across a wide range of frequencies from $20 \mathrm{kHz}$ to $2000 \mathrm{kHz}$. They found no oxidative volatile compounds below $230 \mathrm{~J} / \mathrm{ml}$ in batch systems using $20 \mathrm{kHz}$. The present study used an energy density of $\sim 153 \mathrm{~J} / \mathrm{mL}$. It thus can be assumed that oxidation of lipids did not occur under these experimental conditions.

\section{Conclusion}

This work has shown that the use of sonication for the reduction in milk fat globule size has comparable effects to homogenisation. An increase in the elastic modulus and a decrease in syneresis are observed for cheddar cheese gels prepared using this approach. Interestingly, our results show that low temperature sonication gives similar structural changes to the fat globules to that obtained using high temperature homogenization under the same energy density conditions $(\sim 153 \mathrm{~J} / \mathrm{ml})$. Homogenisation is currently conducted at $50^{\circ} \mathrm{C}$ as a common practice, as the higher temperature liquifies the fat globules, resulting in greater reduction of fat globule size. The use of sonication at low temperature may offer major benefits, as it 
homogenisation to achieve similar size reductions; as the total energy demand would decrease. However, in the present case, the use of such sonication led to fat separation from the gel structure rather than an effective incorporation. Hence, careful consideration of processing parameters is needed.

\section{Acknowledgement}

This work was funded by Dairy Innovation Australia Limited and the Australia Research Council. The authors would like to thank the Bio21 Molecular Science \& Biotechnology Institute and the Particulate Fluids Processing Centre, a special research centre of the Australian Research Council at The University of Melbourne, for access to equipment and Dr Martin Palmer from Dairy Innovation for his continuing support of our work. Sally Gras, Sandra Kentish, Muthupandian Ashokkumar and Lydia Ong also acknowledge generous support from the ARC Dairy Innovation Hub (IH120100005).

\section{References}

Ashokkumar, M., Sunartio, D., Kentish S, Mawson, R., Simons, L., Vilkhu, K., Versteeg, C. (2008). Modification of food ingredients by ultrasound to improve functionality: A preliminary study in a model system. Innovative Food Science and Emerging Technologies, 9, 155-160.

Bermudez-Aguirre, D., \& Barbosa Canovas, G.V. (2010). Processing of soft Hispanic cheese (Queso-Fresco”) using thermosoncaited milk: A study of physicochemical characteristics and storage life. Journal of Food Science, 75, 55548-5558.

Bermudez-Aguirre, D., Mawson, R., \& Barbosa-Canovas, G.V. (2008). Microstructure of fat globules in whoLe milk after thermosonication treatment. Journal of Food Science, 73, E325332. 
414 Chandrapala, J., Zisu, B., Palmer, M., Kentish, S.E., \& Ashokkumar, M. (2011). Effects of ultrasound on the thermal and structural characteristics of proteins in reconstituted whey protein concentrate. Ultrasonics Sonochemistry, 18, 951-957.

417 Cho, Y.H., Lucey, J.A., \& Singh, H. (1999). Rheological properties of acid milk gels affected by the nature of the fat globule surface material and heat treatment of milk. International Dairy Journal, 9, 537-546.

Ciron, C.I.E., Gee, V.L., Kelly, A.L., \& Auty, M.A.E. (2012). Modifying the microstructure of low-fat yoghurt by microfluidisation of milk at different pressures to enhance rheological and sensory properties . Food Chemistry, 130, 510-519.

Dalgleish, D.G., Tosh, S.M., \& West, S. (1996).Beyond homogenization: The formation of very small emulsion droplets during the processing of milk by a Microfluidizer . Netherlands Milk and Dairy Journal, 50, 135-148.

Emmons, D.B., Kalab, M., \& Larmond, E. (1980). Milk gel structure. Texture and microstructure in cheddar cheese made from whole milk and from homogenised low fat milk. Journal of Texture Studies, 11, 15-34.

Ghosh, B.C., Steffl, A., Hinrichs, J. \& Kessler, H.G. (1994). Rennet ability of whole milk homogenised before or after pasteurisation. Milchwissenschaft - Milk Science International, 49, 363-367.

Green, N., Hobbs, D.G., Morant, S.V., \& Hill, V.A. (1978). Intermicellar relationships in rennet treated separated milk. 2. Process of gel assembly. Journal of Dairy Research, 45, 413-415.

Green, M.L., Marshall, R.J., \& Glover, F.A. (1983). Influence of homogenisation of rennet curds. Journal of Dairy Research, 50, 341-348.

437 Guinee, T.P., Gorry, C.B., O’Callaghan, D.J., O’Kennedy, B.T., O’Brien, N., \& Fenelon, M.A. (1997). The effects of composition and some processing treatments on the rennet coagulation properties of milk. International Journal of Dairy Journal, 50, 99-106.

440 Hayes, M.G., Fox , P.F., \& Kelly, A.L. (2005). Potential applications of high pressure 441 homogenisation in processing of liquid milk. Journal of Dairy Research, 72, 25-33. 
442 Humbert, G., Driou, A., Guerin, J. \& Alais, C. (1980). Effects of high pressure 443 homogenisation on the properties of milk and its enzymatic clotting charactoristics. Lait, 60, 444 574-594.

445 Juliano, P., Torkamani, A.E., Leong, T., Kolb, V., Watkins, P., Ajlouni, S., Singh, T.K. 446 (2014). Lipid oxidation volatiles absent in milk after selected ultrasound processing. 447 Ultrasonics Sonochemistry, 21, 2165-2175.

448 Kentish, S., Feng, H. (2014), Applications of Power Ultrasound in Food Processing, Annual 449 Reviews in Food Science and Technology. 5, 263-84

450 Koh, L., Chandrapala, J., Zisu, B., Martin, G., Kentish, S. \& Ashokkumar, M. (2014). A 451 comparison of the effectiveness of sonication, high shear mixing and homogenisation on 452 improving heat stability of whey protein solutions. Food Bioprocess Technology, DOI 453 10.1007/S11947-013-1072-1.

454 Lemay, A., Paquin, P., \& Lacroix, C. (1994). Influence of micro fluidization of milk on 455 cheddar cheese composition, color, texture and yield. Journal of Dairy Science, 77, 28704562879.

457 Lopez, C., \& Dufour, E. (2001). The composition of the milk fat globule surface alters the 458 structural characteristics of the coagulum. Journal of Colloid Interface Science, 233, 241459249.

460 Madadlou, A., Mousavi, M.E., Asl, A.K., Emam-Djome, Z., \& Zargaran, M. (2007). Effect of 461 cream homogenization on textural characteristics of low-fat Iranian White cheese. 462 International of Dairy Journal, 17, 547-554.

Metzger, L.E., \& Mistry, V.V. (1995). A new approach using homogenisation of cream in the 464 manufacture of reduced fat cheddar cheese 2.Micostrucure fat globule distribution and free oil. Journal of Dairy Science, 78, 1883-1895.

${ }^{a}$ Michalski, M., Michel, F., \& Geneste, C. (2002a). Appearance of submicronic particles in 467 the milk fat globule size distribution upon mechanical treatment. Lait, 82, 193-208. globules: membrane properties affect the viscoelasticity of milk gels. Journal of Dairy 470 Science, 85, 2451-61. 
471 Michalski, M., Camier, B., Briard, V., Leconte, N., Gassi, J., Goudedranche, H., Michel, F., 472 \& Fauquant, J. (2004). The size of native fat globules affects physicochemical and functional properties of Emmental cheese. Lait, 84, 343-358.

474 Ong, L., Dagastine, R.R., Kentish, S.E., \& Gras, S.L. (2010). Microstructure of milk gel and 475 cheese curd observed using cryo scanning electron microscopy and confocal microscopy. LWT - Food Science and Technology, 44, 1291-1302.

477 Ong, L., Dagastine, R.R., Kentish, S.E., \& Gras, S.L. (2011). Coagulation temperature 478 affects the microstructure and composition of full fat cheddar cheese. Dairy Science and 479 Technology, 44, 1291-1302.

480 Ong, L., Dagastine, R.R., Kentish, S.E., \& Gras, S.L. (2012). The effect of pH at renneting 481 on the microstructure, composition and texture of cheddar cheese. Food Research International, 48, 119-130.

Path, J.W., Gellman, G., Schimdt, D., \& Herforth-Kennedy, C, (1989), Homogenisation of milk prior to cheddar cheese manufacture. Journal of Dairy Science, 72, 2287-2290.

Robson, E.W., \& Dalgleish, D.G. (1984). Coagulation of homogenised milk particles by rennet. Journal of Dairy Research, 51, 417-424.

Sanchez, C., Beauregard J.C., Chassagne M.H. Bimbenet J.J., Hardy, J. (1996). Effects of processing on rheology and structure of double cream cheese. Food Research International, 28, 547-552.

Sandra, S., \& Dalgleish, D.G. (2007).The effect of ultra high-pressure homogenization (UHPH) on rennet coagulation properties of unheated and heated fresh skimmed milk. International Dairy Journal, 17, 1043-1052.

Shaker, R.R., Abu-Jdayl, B., Jumah, R.Y., \& Ibrahim, S.A. (2002). Rheological properties of set yogurt as influenced by incubation temperature and homogenization. Journal of Food Quality, 25, 409-418. homogenisation of raw bovine milk. Effects on fat globule size distribution and microbial inactivation. International Dairy Journal, 13, 427-439. 
499 Titapiccolo, G.I., Alexander, M., \& Corredig, M. (2010). Rennet-induced aggregation of 500 homogenized milk: Impact of the presence of fat globules on the structure of casein gels. 501 Dairy Science and Technology, 90, 623-639.

502 Tosh, S.M., \& Dalgleish, D.G. (1998). The physical properties and renneting characteristics 503 of the synthetic membrane on the fat globules of microfluidized milk. Journal of Dairy 504 Science, 81, 1840-1847.

505 Tunick, M.H., van Hekken, D.L., Cooke, P.H., Smith, P.W., \& Malin, E.L. (2000). Effect of 506 high pressure micro fluidisation on microstrucutre of mozzarella cheese. Leben Technologies, 507 33, 538-544.

508 van Hekken, D.L., Tunick, M.H., Marlin, E.L., \& Holsinger, V.H. (2007). Rheology and melt 509 characterisation of low fat and full fat mozzarella cheese made from micro fluidised milk. $510 \quad L W T, 40,89-98$.

511 Xiong, Y.L., Aguilera, J.M., \& Kinsella, J.E. (1991). Emulsified milk fat effects on rheology of acid induced milk gels. Journal of Food Science, 56, 920-925.

513 Ye, A., Anema, S.G., \& Singh, H. (2004). High pressure induced interactions between milk 514 fat globule membrane proteins and skim milk proteins in whole milk. Journal of Dairy 515 Science, 87, 4013-4022.

516 Yi-ran, Y.R., Lee, S.K., \& Anema, S.G. (2011). Effect of heat treatments and homogenisation 517 pressure on the acid gelation properties of recombined whole milk. Food Chemistry, 129, $518 \quad 463-471$.

519 Zamora, A., Ferragut, V., Jaramillo, P.D. , Guamis, B., \& Trujillo, A.J. (2006). Effects of 520 UHP homogenisation on the cheese making properties of milk. Journal of Dairy Science, 90, 521 13-23.

522 Zhou, N. \& Mulvaney, S.J. (1998). Effect of milk fat, casein:water ratio and temperature on 523 the viscoelastic properties of rennet casein gels. Journal of Dairy Science, 81, 2561-2571.

525 Zisu, B., Lee, J., Chandrapala, J., Bhaskaracharya, R., Palmer, M., Kentish, S.E., \& 526 Ashokkumar, M. (2011). Effect of ultrasound on the physical and functional properties of 527 reconstituted whey protein powders. Journal of Dairy Research, 78, 226-232. 
531 Table 1: Composition of milk, retentate, concentrate and cream

532 Table 2: D[4,3] of fat globules present in untreated/treated raw milk, UF retentate and cream 533 samples

534 Table 3: Gel properties of rennet and acid gels made using three different cheese milks

535

536

537

538

539

540

541

542

543

544

545

546

547

548

549

550

551

552

553

\section{Figure Captions}

Fig. 1. CLSM of native and sonicated (A) raw milk \& (B) UF retentate under two different power levels as a function of treatment time. (i) The Nile red stained fat globules appear red and the FCF fast green stained protein appears green. (ii) The WGA488 stained MFGM appears red and the FCF fast green stained protein appears green.

Fig. 2. CSLM of sonicated (50 W) cream under different time intervals. (A) Nile red stained fat globules appear red and the FCF fast green stained protein appears green. (B) The WGA488 stained MFGM appears red and the FCF stained protein appears green. The images were taken using 100x objective lens with 2x (A-bottom \& B-top row) and 4x (A-top \& Bbottom row) digital magnifications. Thick arrows indicate grape like fat globule structure. Thin arrows indicate native MFGM.

Fig. 3. CLSM of cream sonicated at different times under two temperature conditions $<10^{\circ} \mathrm{C}$ and $50^{\circ} \mathrm{C}$. The Nile red stained fat appears red and the FCF fast green stained protein appears green.

Fig. 4. Particle size distribution of the fat globules present in native cream $(\mathbf{A})$, cream which is homogenised at $10^{\circ} \mathrm{C}(\boldsymbol{\square})$ and at $50^{\circ} \mathrm{C}(\square)$ and cream samples which are sonicated at $10^{\circ} \mathrm{C}$ $(\bullet)$ and at $50^{\circ} \mathrm{C}(\mathrm{o})$ under the same energy density conditions $(153 \mathrm{~J} / \mathrm{ml})$. 
554 Fig. 5. CLSM of cream homogenised at (i) $<10^{\circ} \mathrm{C} \&$ (ii) $50^{\circ} \mathrm{C}$ for (A) the Nile red stained fat 555 globules appear red and the FCF fast green stained protein appears green and (B) WGA488 556 stained MFGM appears red and the FCF stained protein appears green. The images within 557 (A) and (B) were taken using 100x objective lens with $2 \mathrm{x}$ and $4 \mathrm{x}$ digital magnifications for 558 top and bottom images respectively.

559 Fig. 6. Storage module (G') of different cheese-milk preparations during gelation for (A) 560 rennet-induced gel and (B) acid-induced gel. Black line: SM, SMC and native cream 561 (control); Light grey line: SM, SMC with sonicated cream $\left(50 \mathrm{~W} / 1\right.$ min at $\left.<10^{\circ} \mathrm{C}\right)$; and Dark 562 Grey line: SM, SMC with homogenised cream $\left(80\right.$ bar at $\left.50^{\circ} \mathrm{C}\right)$. The result presented is a 563 representative graph of three trials.

564 Fig. 7: CSLM of (A) rennet-induced \& (B) acid-induced gels formed using 3 different 565 cheese-milk systems. (i) SM, SMC and native cream (control), (ii) SM, SMC with 566 homogenised cream $\left(80 \mathrm{bar} /\right.$ at $\left.50^{\circ} \mathrm{C}\right)$ and (iii) $\mathrm{SM}$, SMC with sonicated cream $(50 \mathrm{~W} / 1 \mathrm{~min}$ at $\left.567<10^{\circ} \mathrm{C}\right)$. The Nile red stained fat appears red and the FCF fast green stained protein appears 568 green. The images within (A) and (B) were taken using 100x objective lens with $2 \mathrm{x}$ and $4 \mathrm{x}$ 569 digital magnifications for top and bottom images, respectively. 
Figure 1

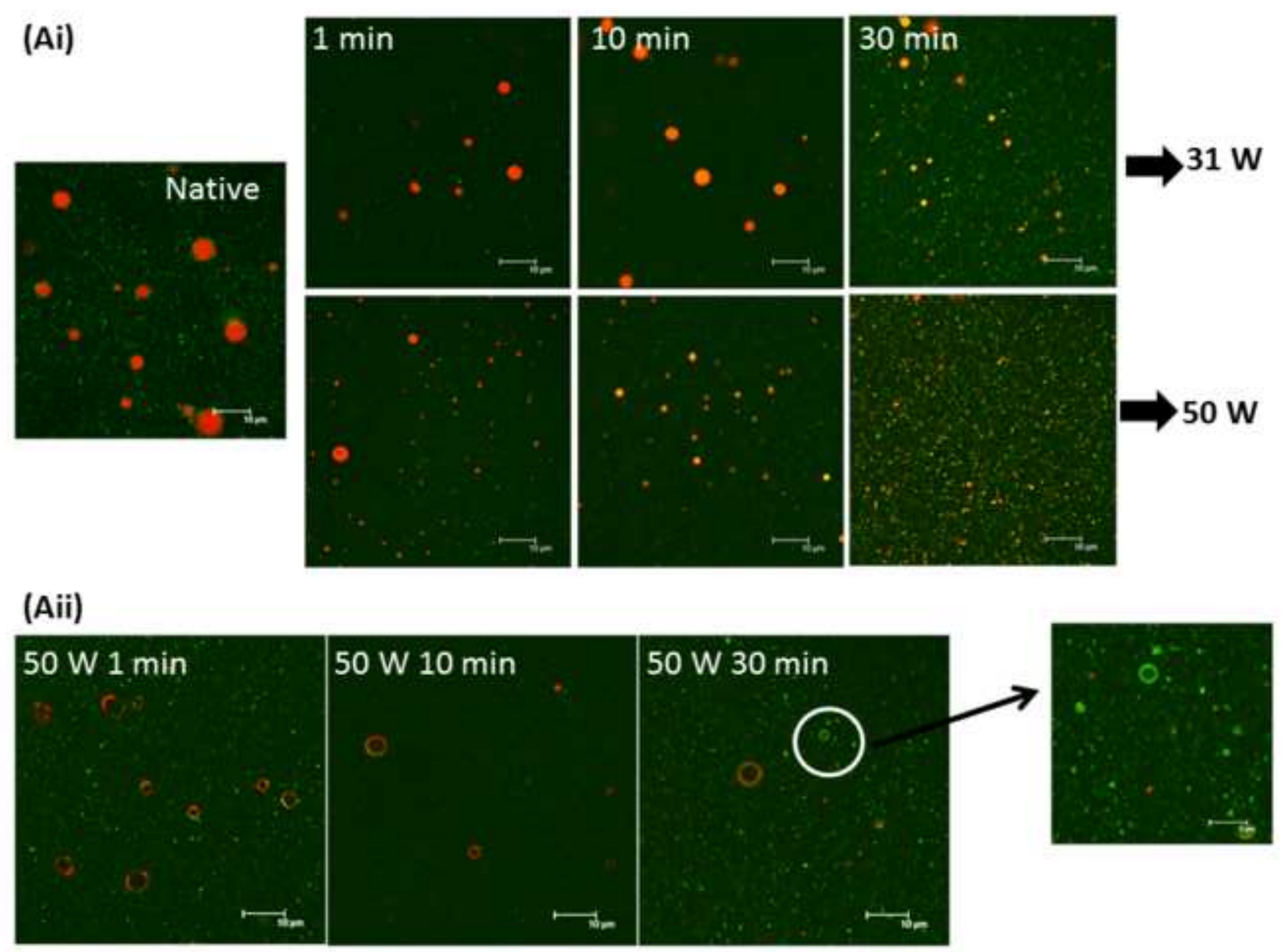


(Bi)

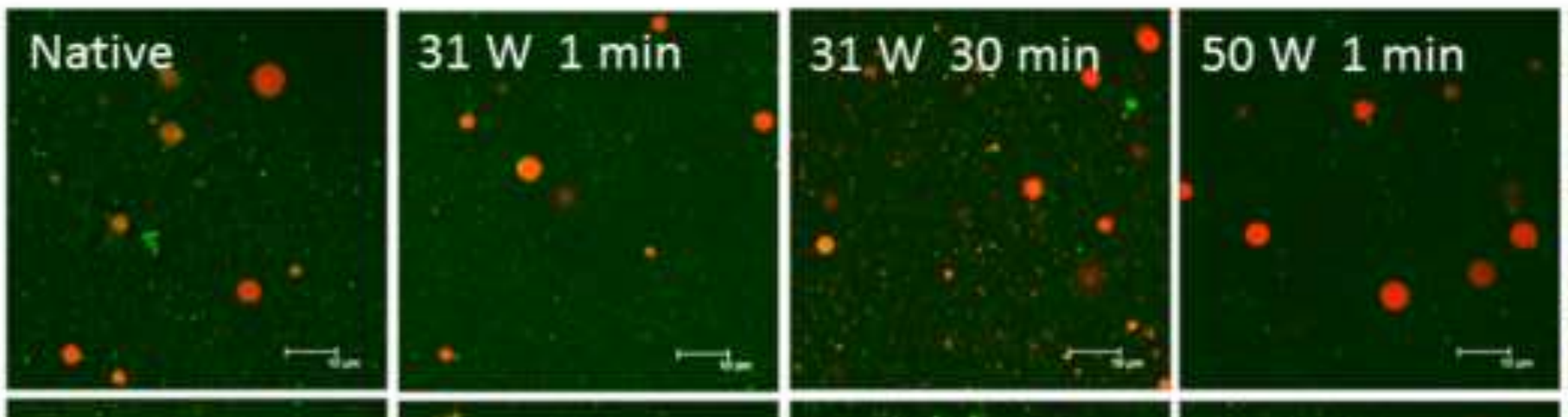

(Bii)
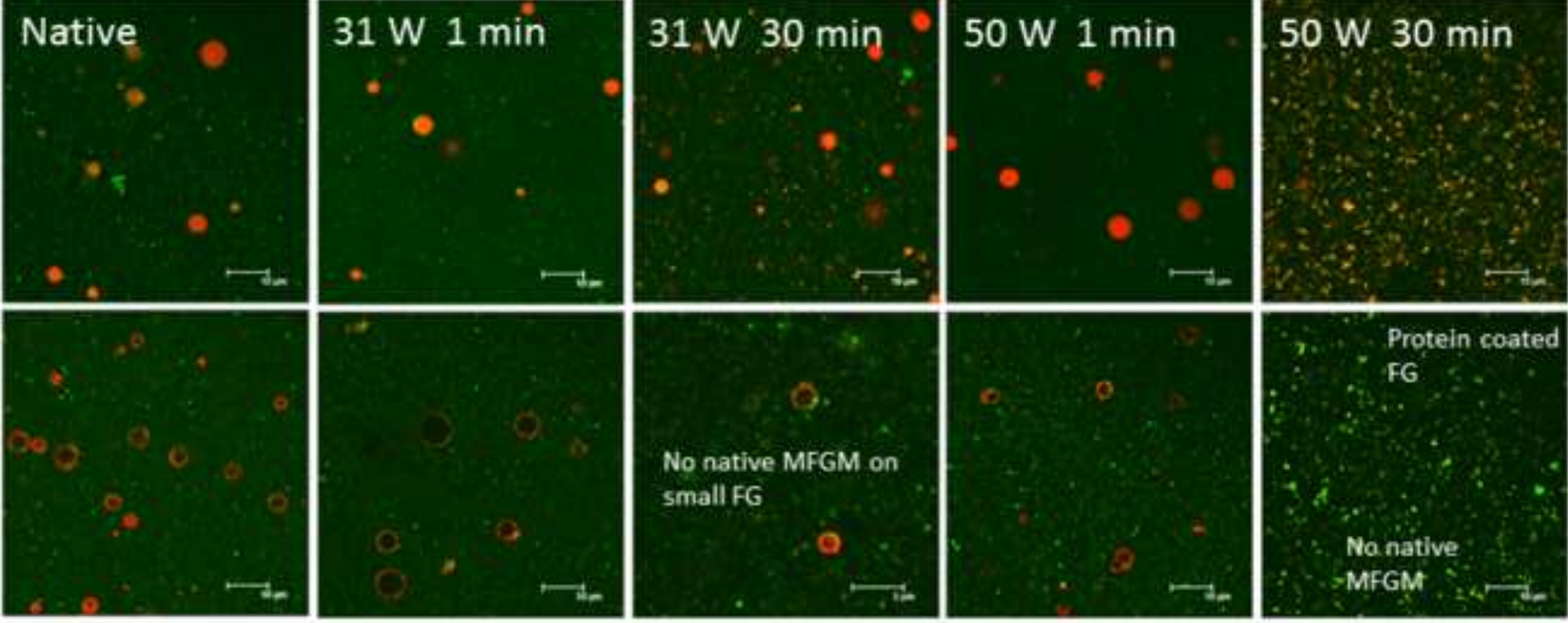
Figure 2

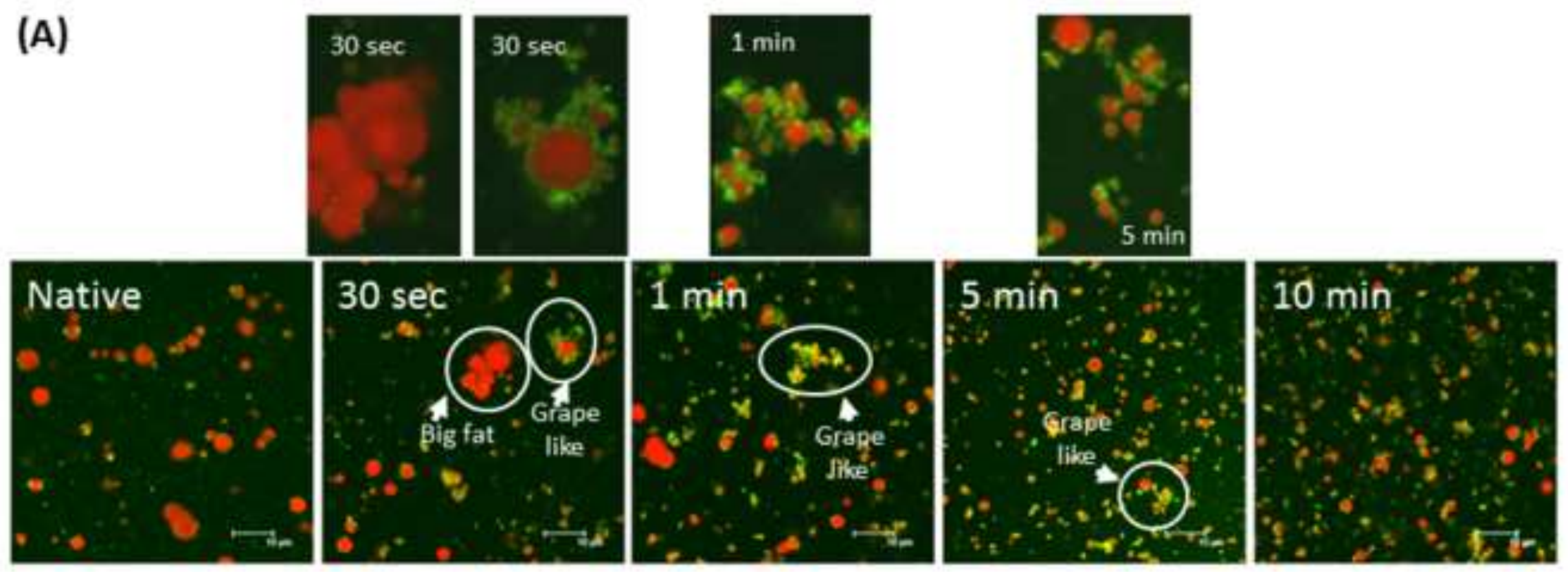


(B)

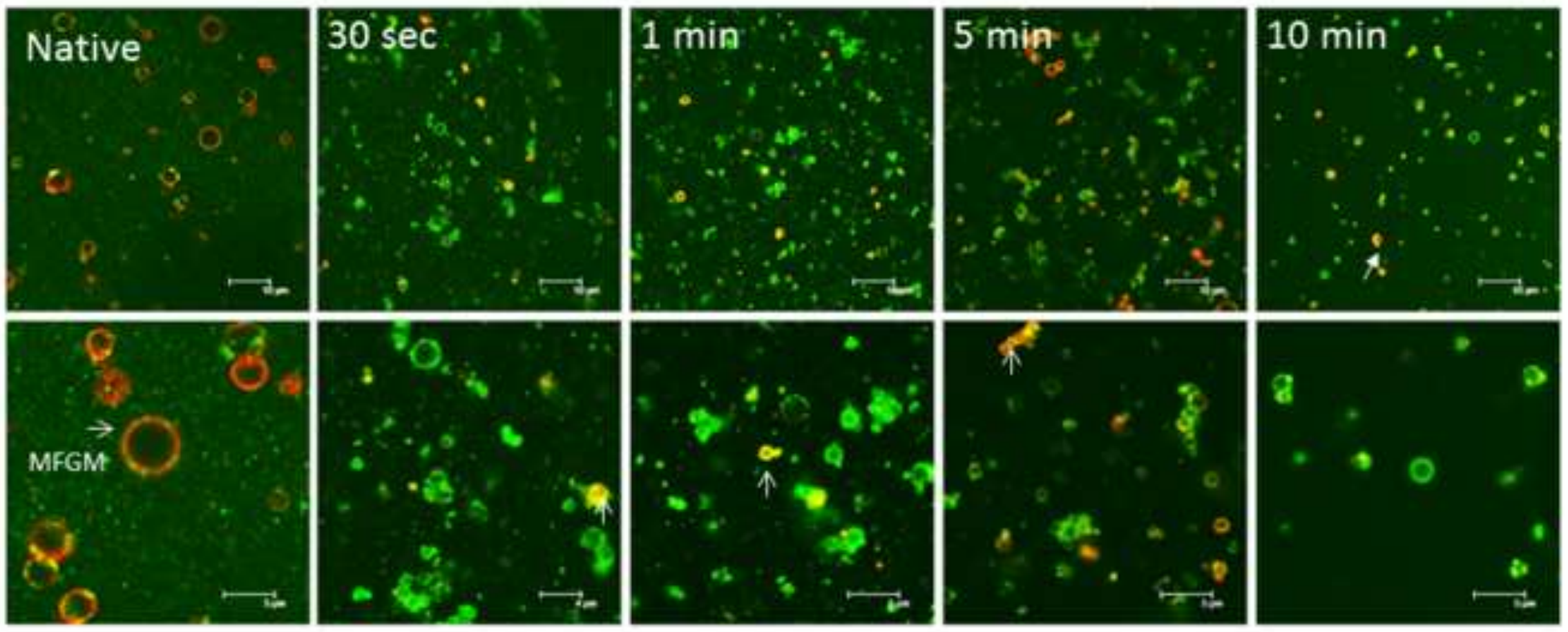


Click here to download high resolution image

Figure 3

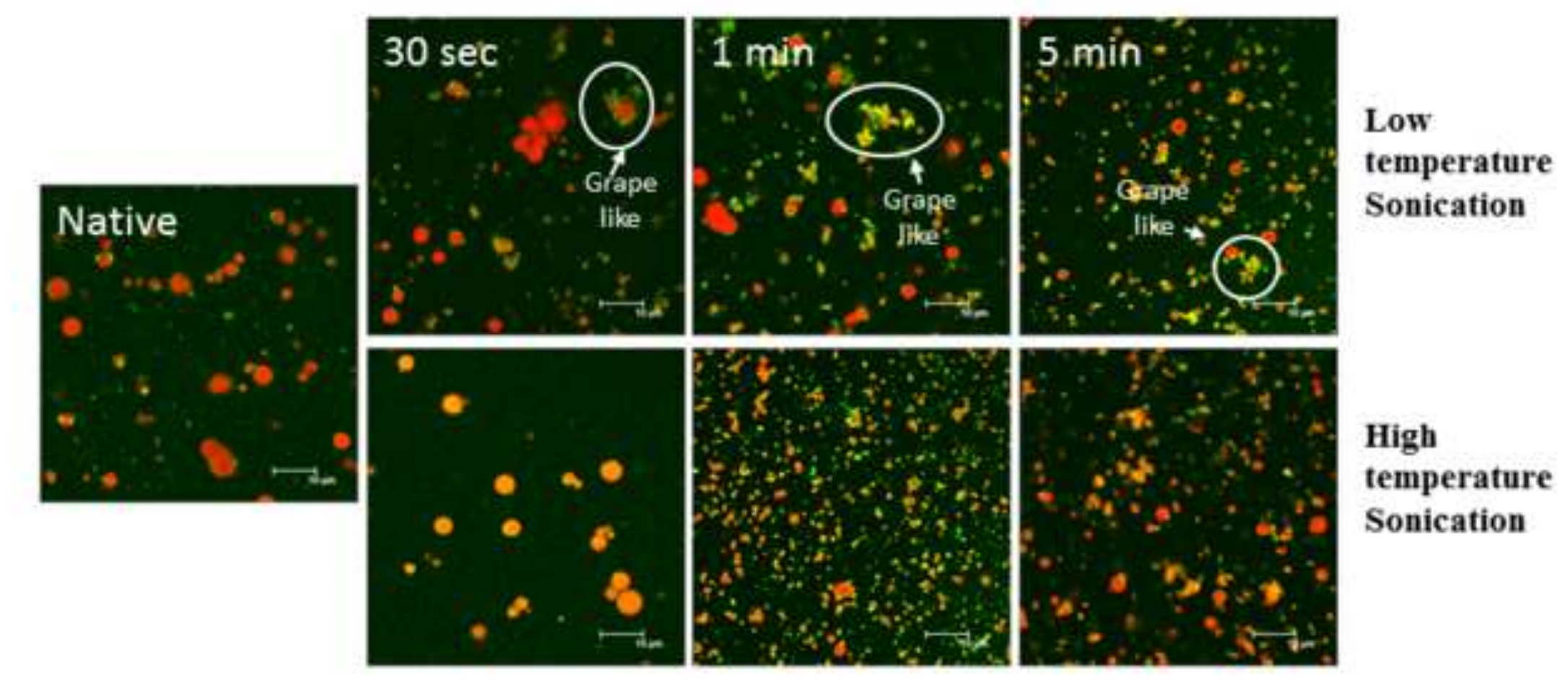

Low temperature Sonication

High Sonication 


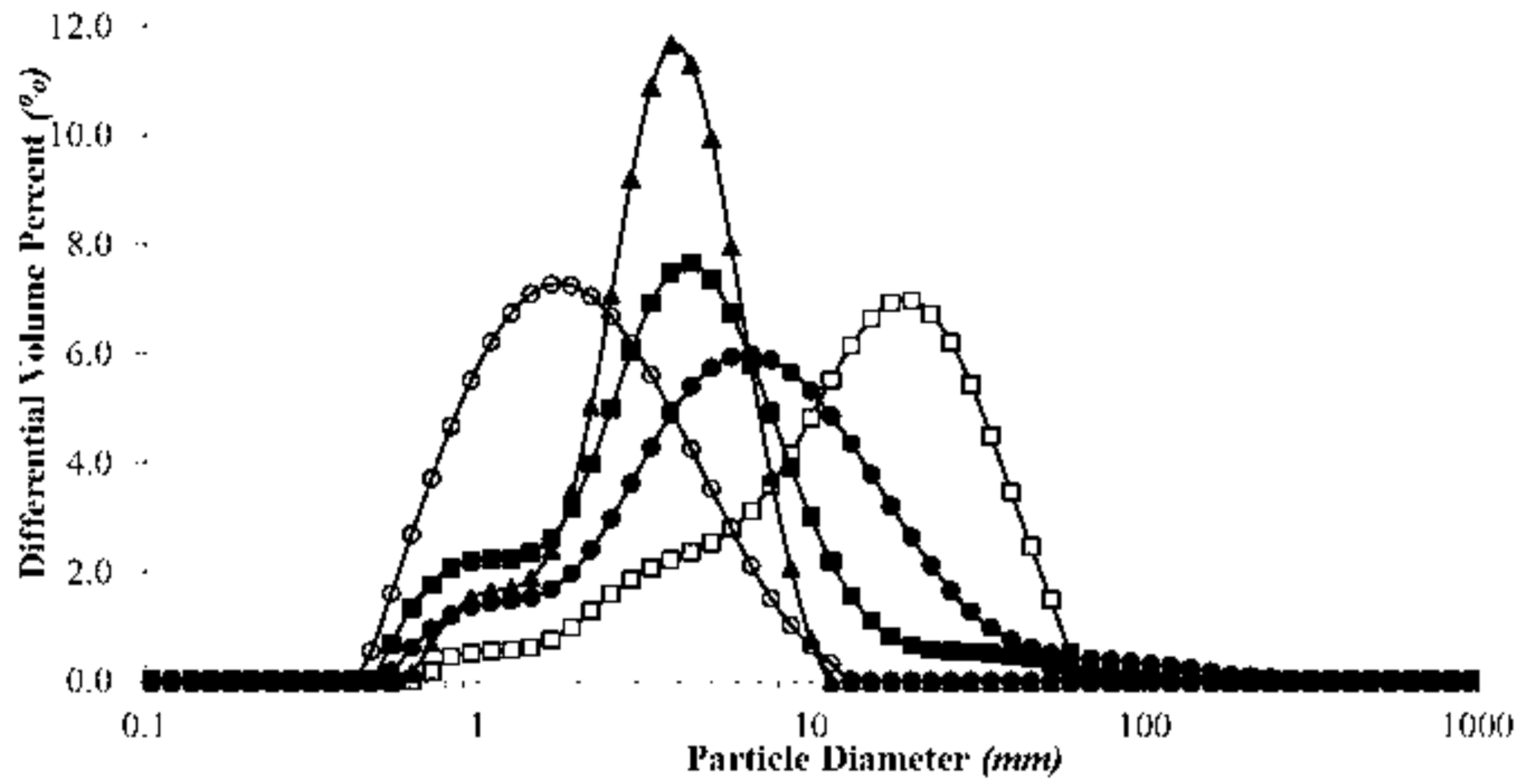


(Ai)
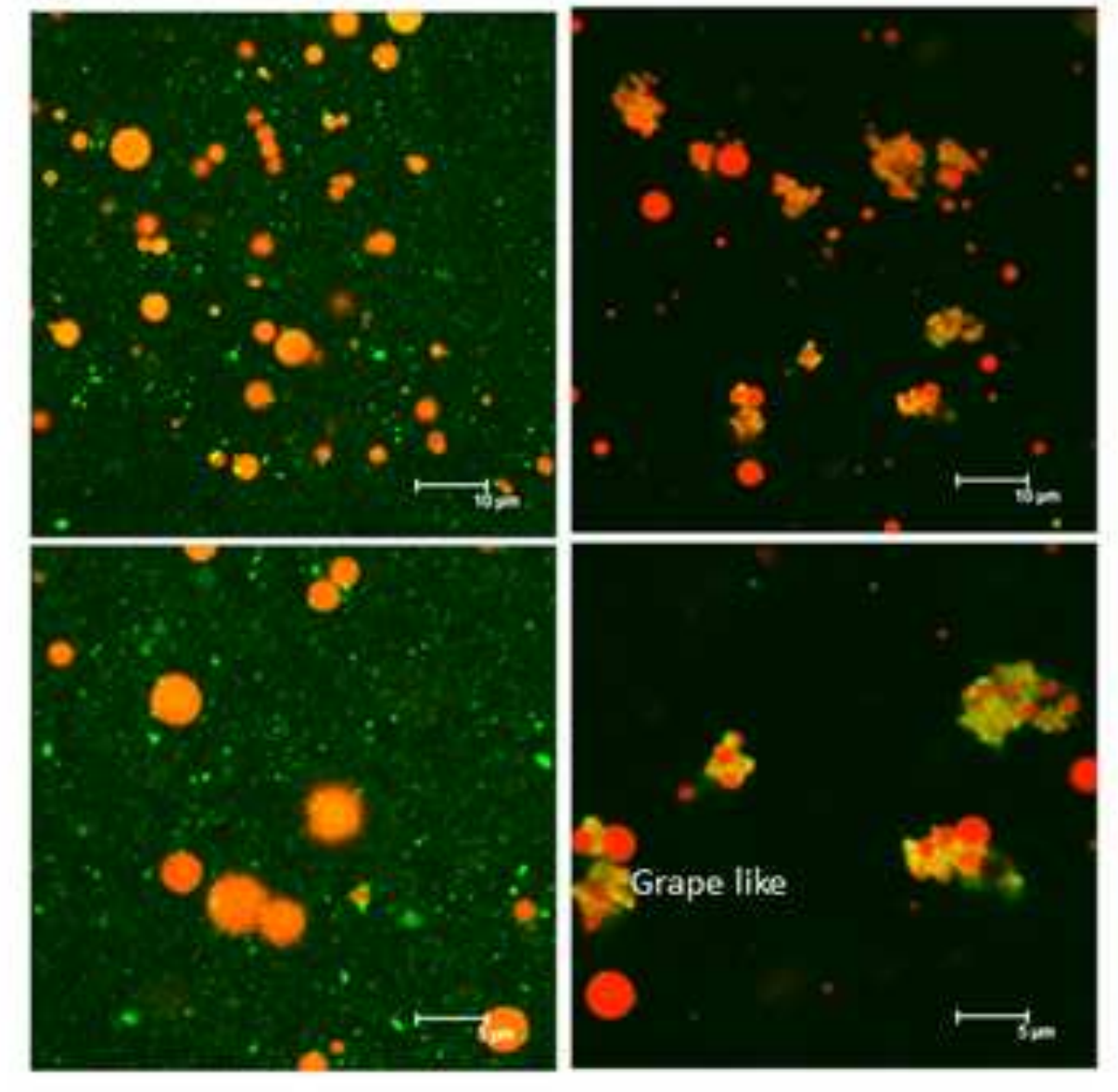

(Aii)
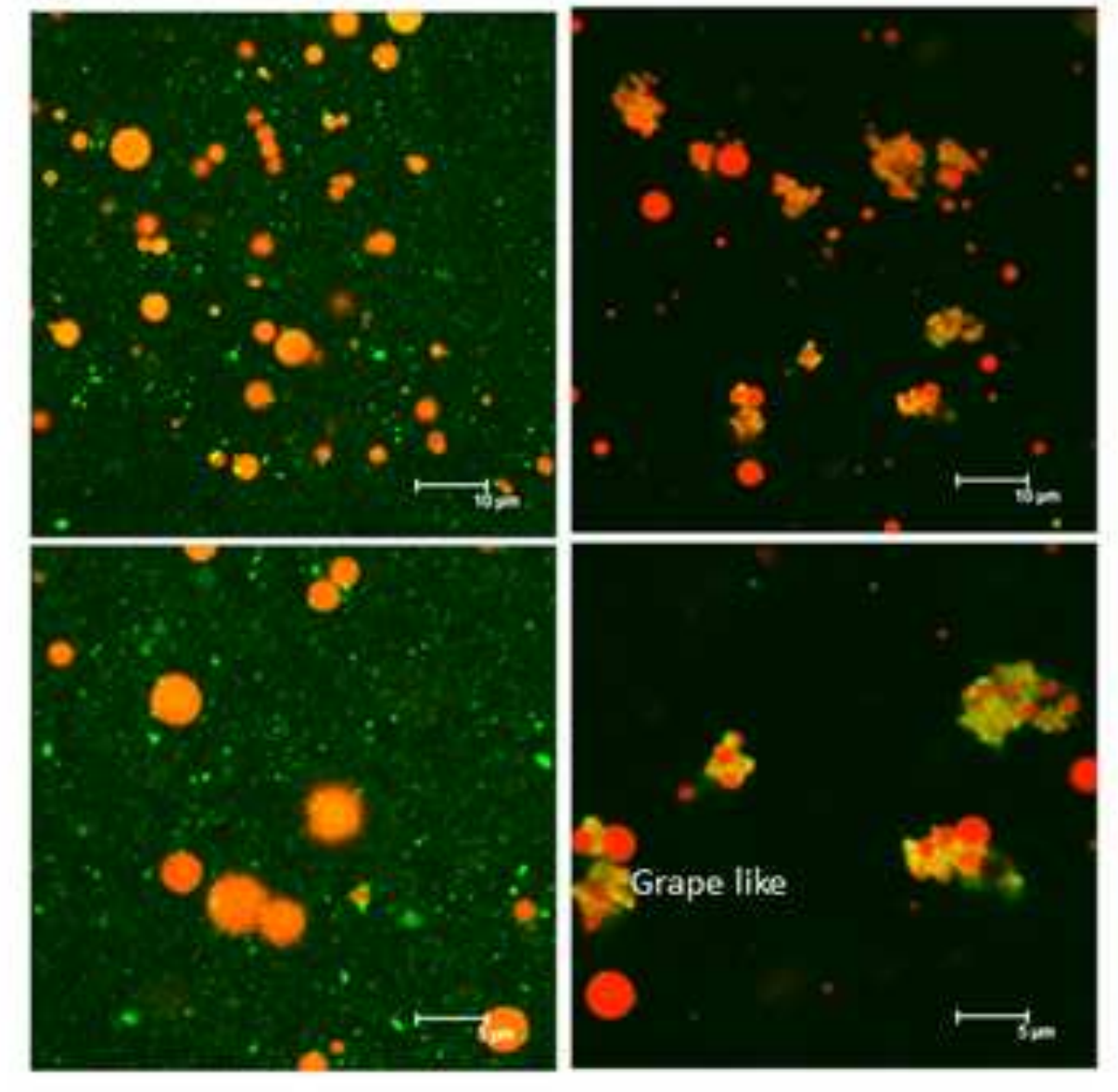

(Bi)

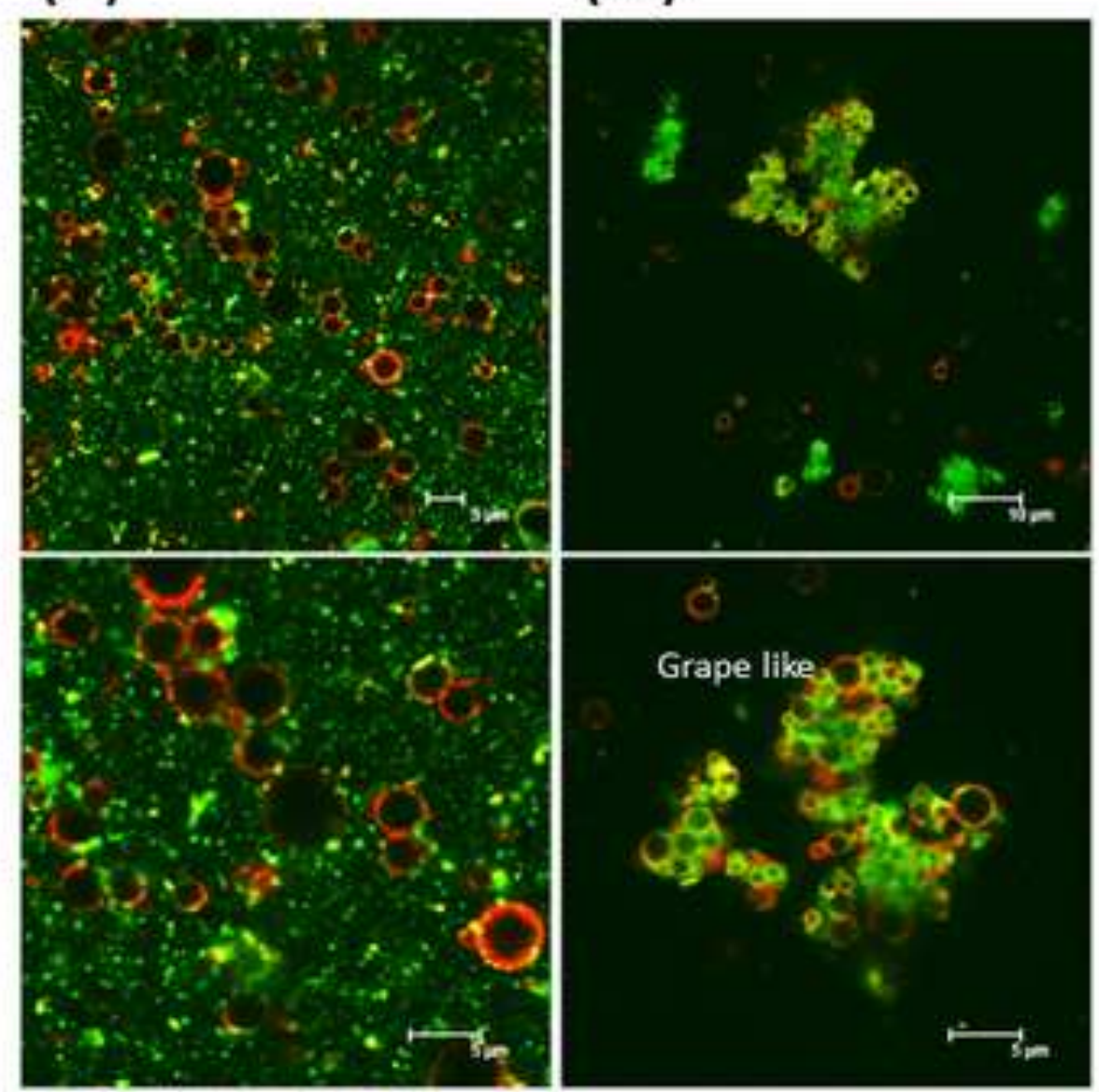

(Bii)

Grape like, 19
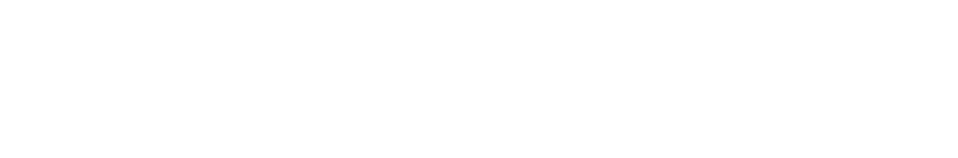
Click here to download high resolution image

(A)

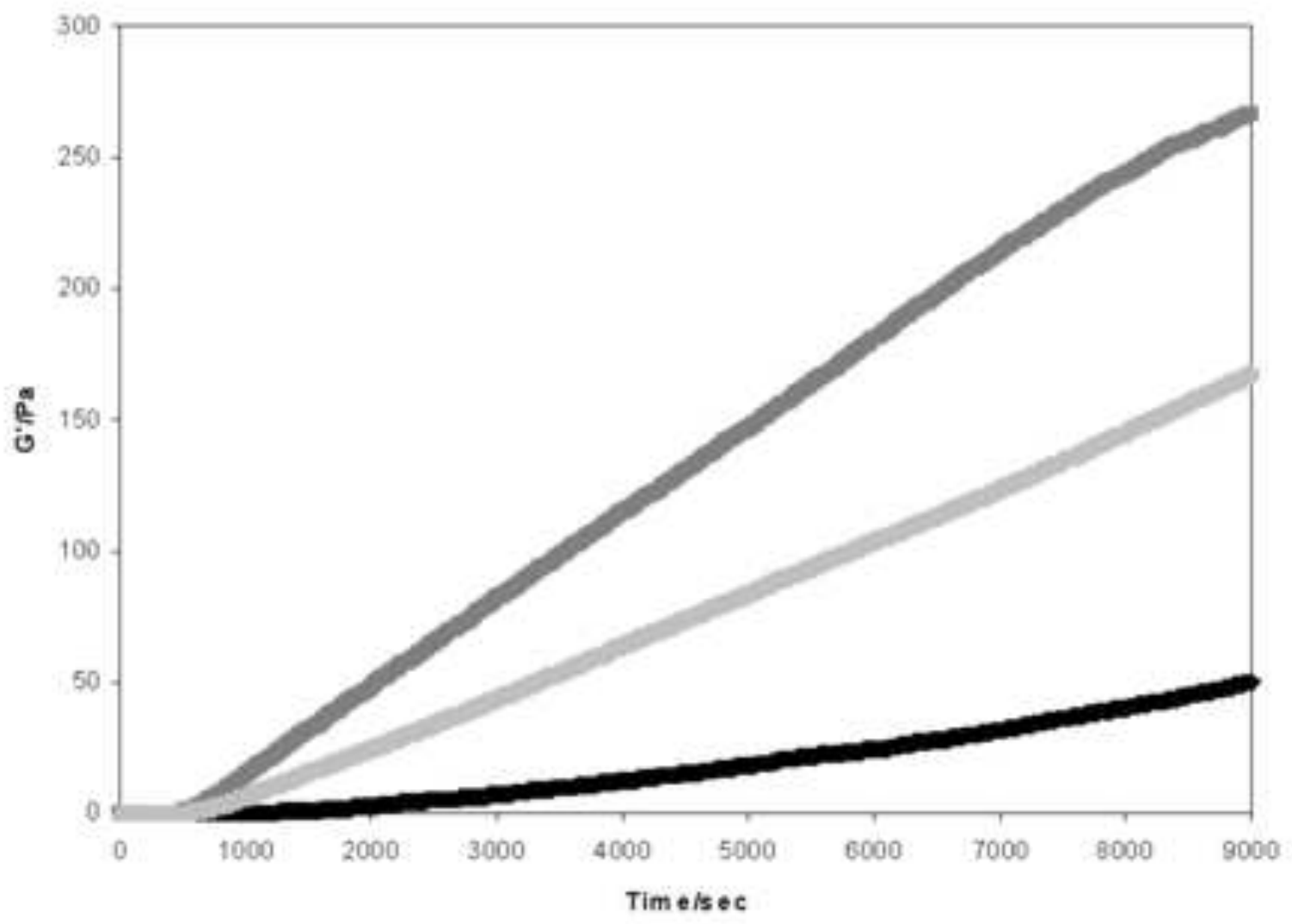

(B)

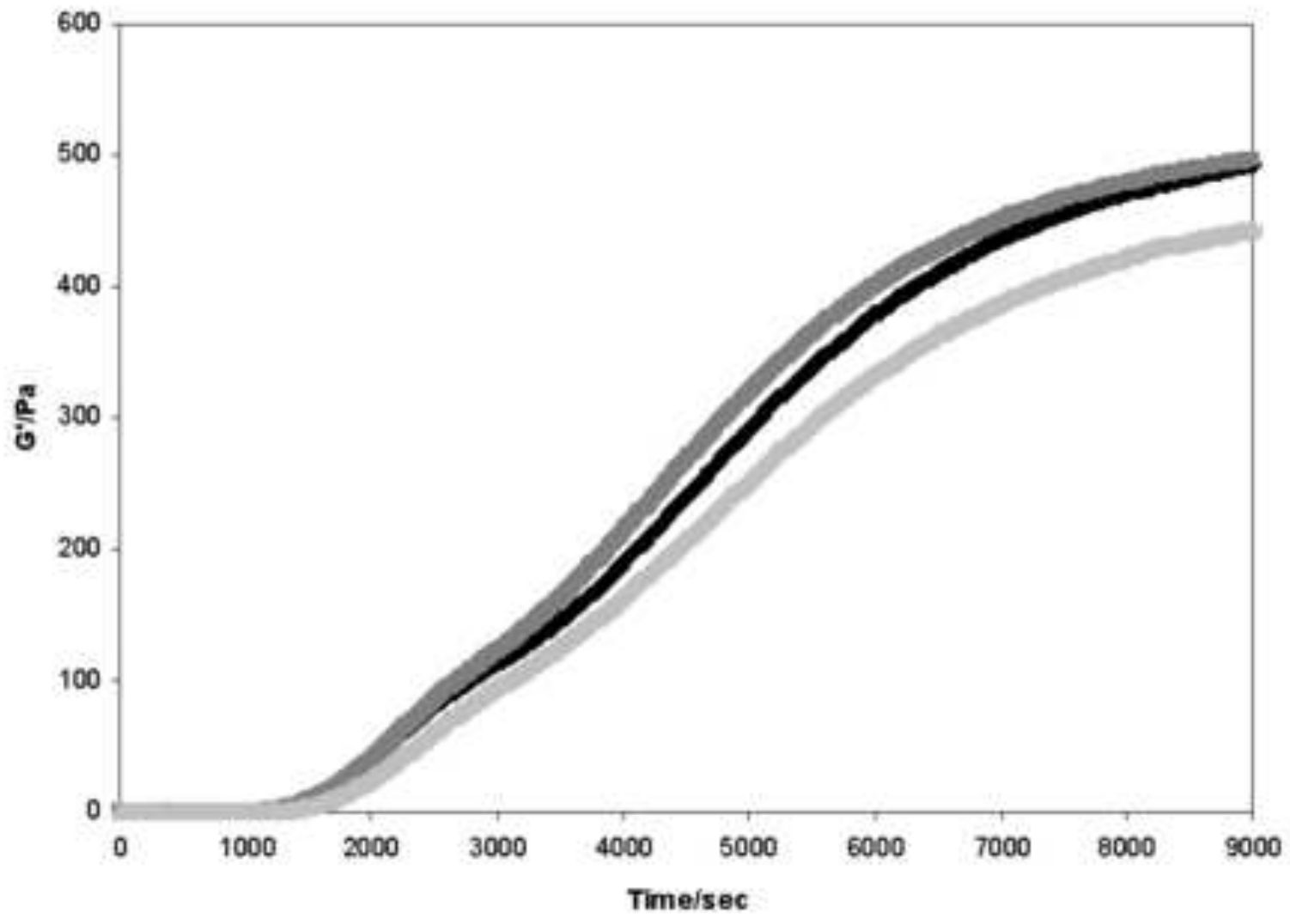


Click here to download high resolution image

Figure 7
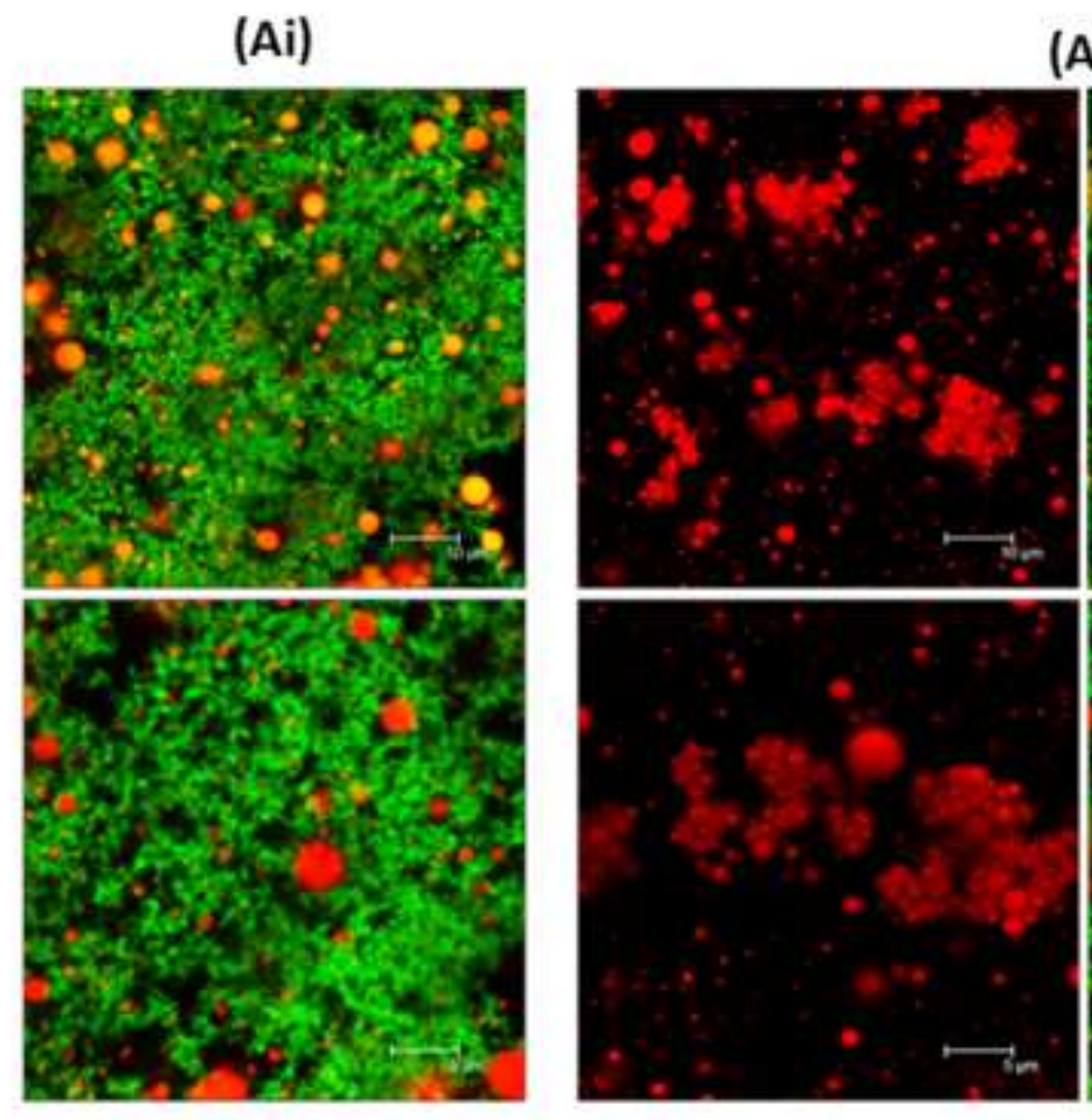

(Aii)

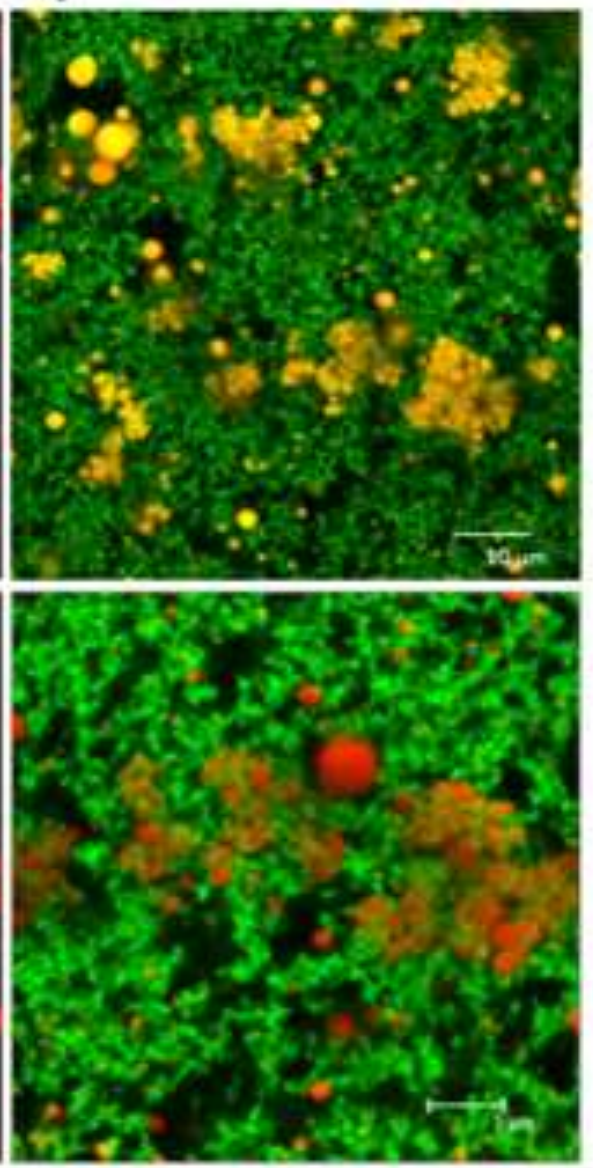

(Aiii)
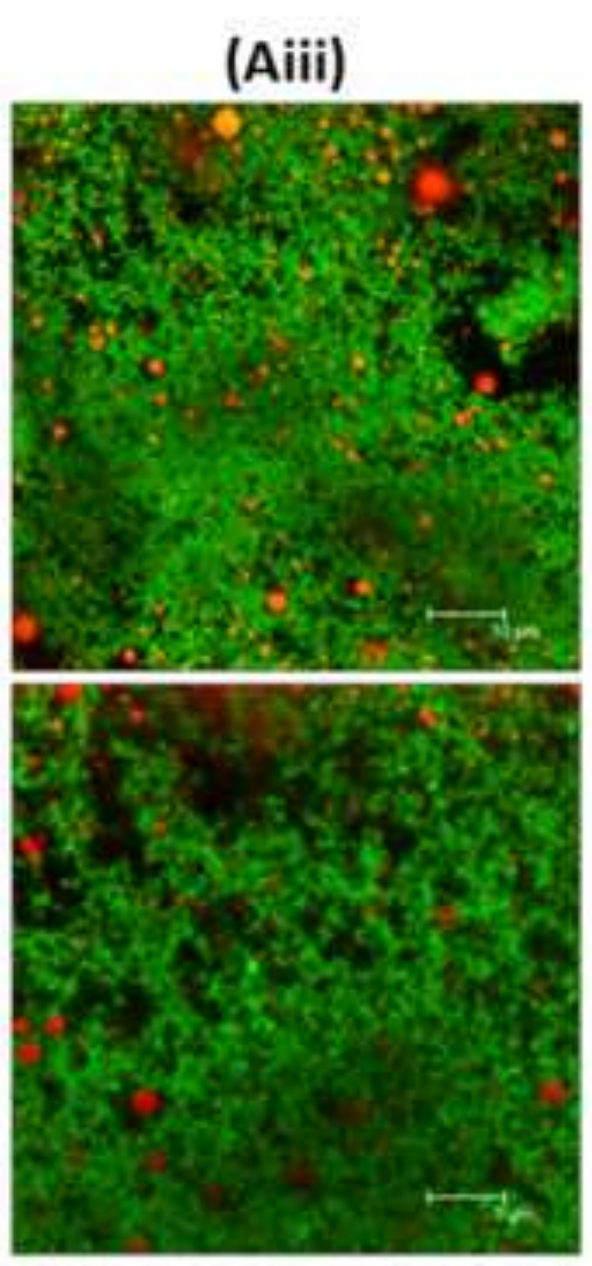
Click here to download high resolution image

Figure 7

(Bi)
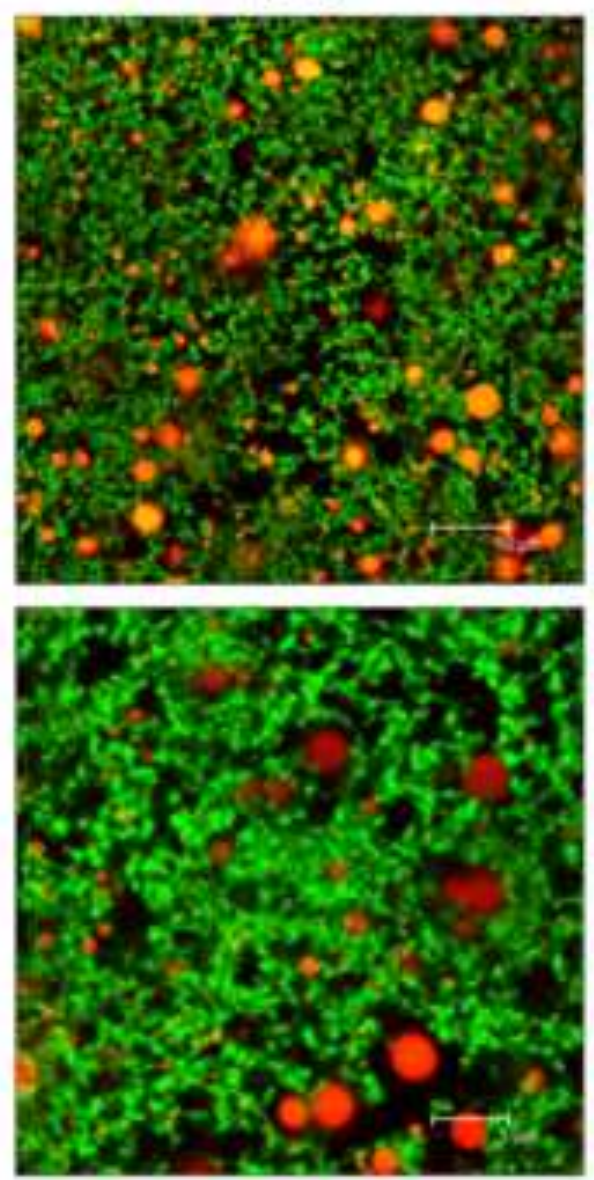

(Bii)
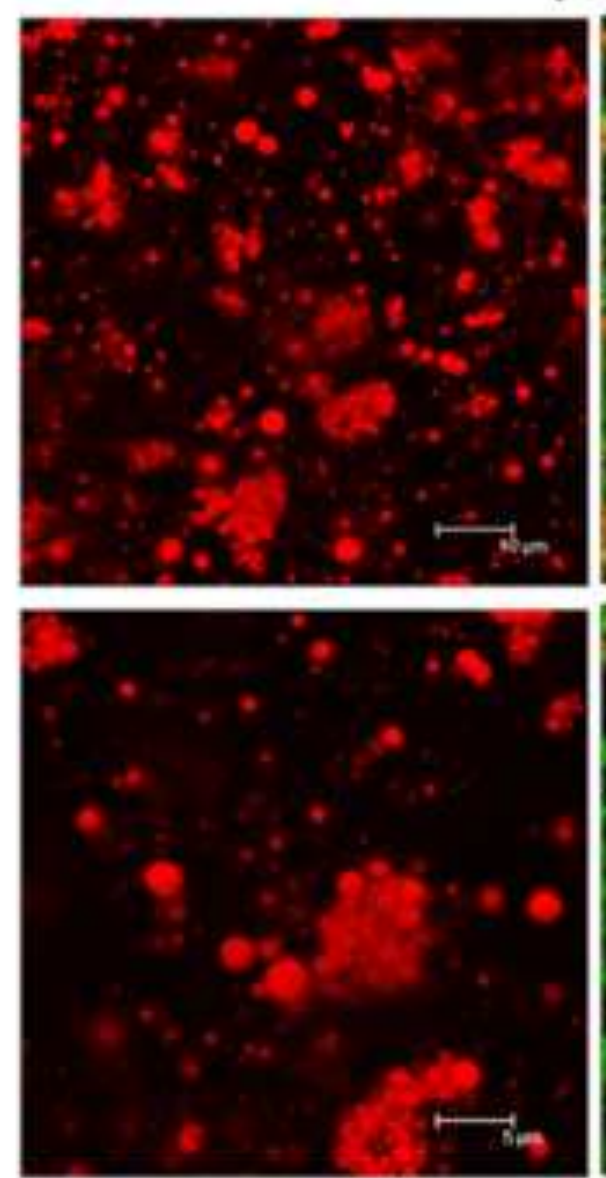
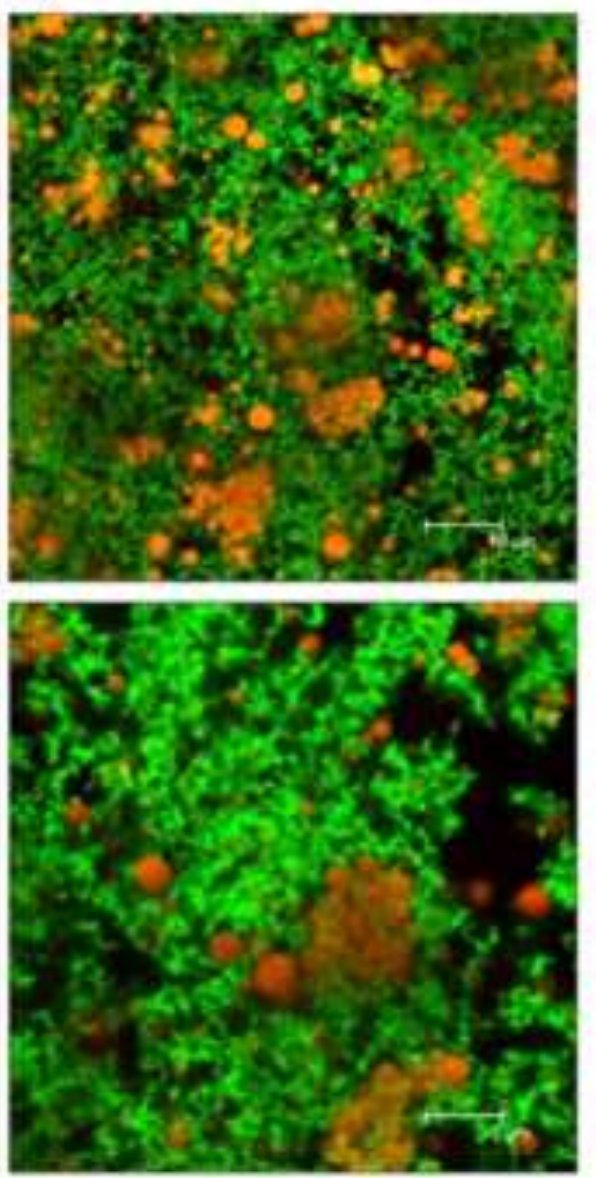

(Biii)
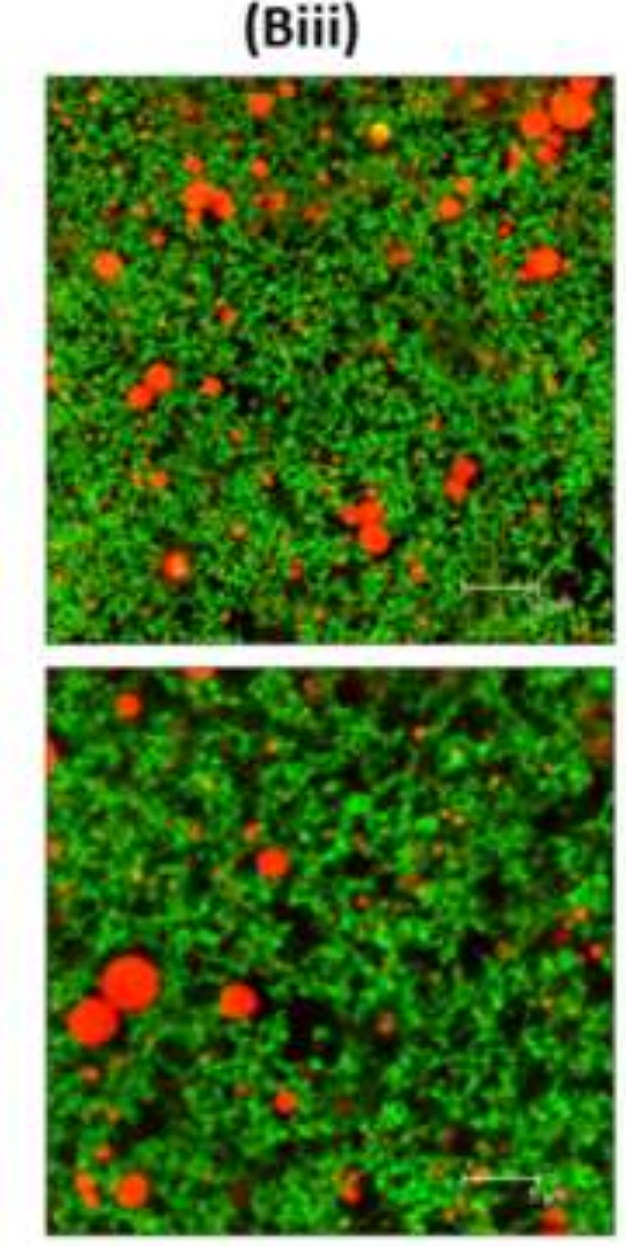
Table 1: Composition of milk, retentate, concentrate and cream

\begin{tabular}{cccccc}
\hline Composition & Raw milk & UF retentate & SMC & Skim milk & Cream \\
\hline Protein & $3.6 \pm 0.2$ & $7.1 \pm 0.4$ & $13.8 \pm 0.1$ & $3.68 \pm 0.11$ & $2.1 \pm 0.2$ \\
Fat & $4.2 \pm 0.2$ & $8.2 \pm 0.6$ & $0.22 \pm 0.03$ & $0.08 \pm 0.01$ & $42.0 \pm 1.0$ \\
\hline
\end{tabular}

Data are mean \pm standard deviation of mean $(n=3) . S M C=$ Skim Milk Concentrate 
Table 2: D[4,3] of fat globules present in untreated/treated raw milk, UF milk and cream samples

\begin{tabular}{|c|c|c|c|c|c|c|}
\hline \multicolumn{3}{|c|}{ Treatment } & \multirow{2}{*}{$\begin{array}{c}\text { Raw Milk } \\
3.76 \pm 0.04\end{array}$} & \multirow{2}{*}{$\begin{array}{c}\mathbf{U F} \\
\text { Retentate }\end{array}$} & \multirow{2}{*}{$\begin{array}{c}\begin{array}{c}\text { Cream } \\
\text { Without SDS }\end{array} \\
4.03 \pm 0.08\end{array}$} & \multirow{2}{*}{$\begin{array}{c}\text { Cream } \\
\text { With SDS } \\
\end{array}$} \\
\hline Native & & & & & & \\
\hline \multirow[t]{3}{*}{$31 \mathrm{~W}$} & $1 \mathrm{~min}$ & $5^{\circ} \mathrm{C}$ & $3.68 \pm 0.03$ & $4.05 \pm 0.04$ & & \\
\hline & $10 \mathrm{~min}$ & $5^{\circ} \mathrm{C}$ & $3.69 \pm 0.04$ & $3.88 \pm 0.04$ & & \\
\hline & $30 \mathrm{~min}$ & $50^{\circ} \mathrm{C}$ & $1.49 \pm 0.02$ & $2.96 \pm 0.03$ & & \\
\hline \multirow[t]{4}{*}{$50 \mathrm{~W}$} & $30 \mathrm{sec}$ & $5^{\circ} \mathrm{C}$ & & & $2.4 \pm 0.4$ & \\
\hline & $1 \mathrm{~min}$ & $5^{\circ} \mathrm{C}$ & $3.63 \pm 0.03$ & $4.11 \pm 0.03$ & $2.3 \pm 0.2$ & \\
\hline & $10 \mathrm{~min}$ & $5^{\circ} \mathrm{C}$ & $1.30 \pm 0.01$ & $0.26 \pm 0.01$ & $1.63 \pm 0.09$ & \\
\hline & $30 \mathrm{~min}$ & $5^{\circ} \mathrm{C}$ & $0.16 \pm 0.002$ & $0.16 \pm 0.003$ & & \\
\hline \multirow[t]{4}{*}{$50 \mathrm{~W}$} & $30 \mathrm{sec}$ & $<10^{\circ} \mathrm{C}$ & & & $24.4 \pm 1.1$ & $9.2 \pm 0.9$ \\
\hline & $1 \mathrm{~min}$ & $<10^{\circ} \mathrm{C}$ & & & $10.9 \pm 0.9$ & $5.25 \pm 0.13$ \\
\hline & $5 \mathrm{~min}$ & $<10^{\circ} \mathrm{C}$ & & & $5.50 \pm 0.06$ & $2.16 \pm 0.05$ \\
\hline & $10 \mathrm{~min}$ & $<10^{\circ} \mathrm{C}$ & & & $3.35 \pm 0.04$ & $1.58 \pm 0.04$ \\
\hline
\end{tabular}

Data are mean \pm standard deviation of mean $(n \geq 3)$. 
Table 3: Gel properties of rennet and acid gels made using three different cheese milks

\begin{tabular}{cccc}
\hline Measurement & Control & Homogenisation & Sonication \\
\hline Rennet & & & \\
Yield Stress/g & $4.4 \pm 0.2$ & $4.1 \pm 0.4$ & $3.8 \pm 0.5$ \\
Gel Strength/g & $5.5 \pm 0.2$ & $5.1 \pm 0.3$ & $4.9 \pm 0.4$ \\
Gelation times/min & $41 \pm 1^{\mathrm{a}}$ & $12.1 \pm 0.8^{\mathrm{b}}$ & $15.1 \pm 1.1^{\mathrm{c}}$ \\
Syneresis/\% w/w & $60 \pm 3^{\mathrm{a}}$ & $21 \pm 3^{\mathrm{b}}$ & $37 \pm 7^{\mathrm{c}}$ \\
Final G'/Pa & $50 \pm 3^{\mathrm{a}}$ & $267 \pm 10^{\mathrm{b}}$ & $168 \pm 7^{\mathrm{c}}$ \\
Acid & & & \\
Yield Stress/g & $16.4 \pm 1.3$ & $17.1 \pm 1.1$ & $16.8 \pm 0.9$ \\
Gel Strength/g & $19 \pm 2$ & $21 \pm 1$ & $17 \pm 1$ \\
Gelation times/min & $22 \pm 2$ & $22 \pm 1$ & $24 \pm 1$ \\
Syneresis/\% & $24 \pm 2$ & $20 \pm 2$ & $18 \pm 2$ \\
Final G'/Pa & $493 \pm 13$ & $497 \pm 15$ & $443 \pm 15$ \\
\hline
\end{tabular}

${ }^{\mathrm{abc}}$ Results with different superscripts are significantly different $(\mathrm{P}<0.05)$ 


\section{University Library}

\section{- M M N E R VA A gateway to Melbourne's research publications}

Minerva Access is the Institutional Repository of The University of Melbourne

Author/s:

Chandrapala, J;Ong, L;Zisu, B;Gras, SL;Ashokkumar, M;Kentish, SE

Title:

The effect of sonication and high pressure homogenisation on the properties of pure cream

Date:

2016-02-01

Citation:

Chandrapala, J., Ong, L., Zisu, B., Gras, S. L., Ashokkumar, M. \& Kentish, S. E. (2016). The effect of sonication and high pressure homogenisation on the properties of pure cream. INNOVATIVE FOOD SCIENCE \& EMERGING TECHNOLOGIES, 33, pp.298-307. https:// doi.org/10.1016/j.ifset.2015.11.023.

Persistent Link:

http://hdl.handle.net/11343/123251 